Procedures for Addressing Uncertainty and Variability in Exposure to Characterize Potential Health Risk From Trichloroethylene Contaminated Groundwater at Beale Air Force Base in California

J.I. Daniels, K.T. Bogen, L.C. Hall

\title{
September 1, 1999
}

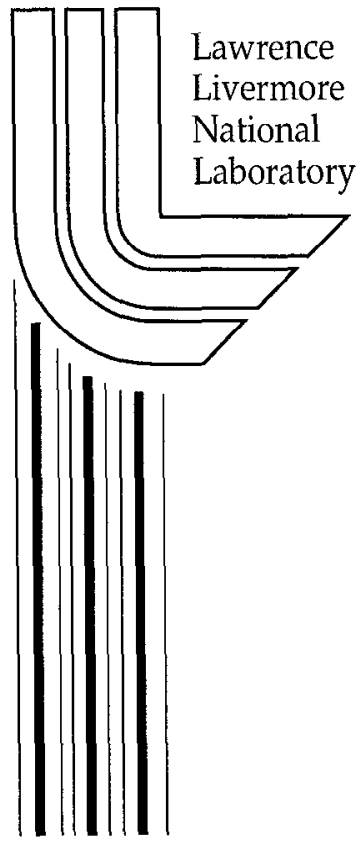





\section{DISCLAIMER}

This document was prepared as an account of work sponsored by an agency of the United States Government. Neither the United States Government nor the University of California nor any of their employees, makes any warranty, express or implied, or assumes any legal liability or responsibility for the accuracy, completeness, or usefulness of any information, apparatus, product, or process disclosed, or represents that its use would not infringe privately owned rights. Reference herein to any specific commercial product, process, or service by trade name, trademark, manufacturer, or otherwise, does not necessarily constitute or imply its endorsement, recommendation, or favoring by the United States Government or the University of California. The views and opinions of authors expressed herein do not necessarily state or reflect those of the United States Government or the University of California, and shall not be used for advertising or product endorsement purposes.

Work performed under the auspices of the U. S. Department of Energy by the University of California Lawrence Livermore National Laboratory under Contract W-7405-Eng-48.

This report has been reproduced directly from the best available copy.

Available to DOE and DOE contractors from the Office of Scientific and Technical Information

P.O. Box 62, Oak Ridge, TN 37831

Prices available from (423) 576-8401

http://apollo.osti.gov/bridge/

Available to the public from the National Technical Information Service

U.S. Department of Commerce 5285 Port Royal Rd., Springfield, VA 22161 http://www.ntis.gov/

OR

Lawrence Livermore National Laboratory Technical Information Department's Digital Library http://www.llnl.gov/tid/Library.html 

Procedures for Addressing Uncertainty and Variability in Exposure to Characterize Potential Health Risk From Trichloroethylene Contaminated Groundwater at Beale Air Force Base in California

J.I. Daniels

K.T. Bogen

L.C. Hall

September 1999 


\section{PREFACE}

This study was designed to accomplish two objectives. The first was to provide to the US Air Force and the regulatory community quantitative procedures that they might want to consider using for addressing uncertainty and variability in exposure to better characterize potential health risk. Such methods could be used at sites where populations may now or in the future be faced with using groundwater contaminated with low concentrations of the chemical trichloroethylene (TCE). The second was to illustrate and explain the application of these procedures with respect to available data for TCE in ground water beneath an inactive landfill site that is undergoing remediation at Beale Air Force Base in California. The results from this illustration provide more detail than the more traditional conservative deterministic, screening-level calculations of risk, also computed for purposes of comparison. Application of the procedures described in this report can lead to more reasonable and equitable risk-acceptability criteria for potentially exposed populations at specific sites. 


\section{ACKNOWLEDGMENT}

This work was performed under the auspices of the U.S. Department of Energy at Lawrence Livermore National Laboratory under contract W-7405-Eng-48. We are especially grateful to the Institute for Environment, Safety, and Occupational Health Risk Analysis (IERA) in the Risk Science Research and Environment (RSRE) Directorate of the U.S. Air Force (USAF)-311th Human System Wing, located at Brooks Air Force Base, TX, USA, for supporting this work, and particularly, USAF Captain V. Caravello and his colleagues, Drs. E. Maull and N. Giardino, for providing important guidance. We also extend special thanks to Drs. J. Christopher and B. Davis, and Mr. C. Ridenour of the State of California Environmental Protection Agency (CalEPA), Department of Toxic Substances Control (DTSC), for furnishing technical advice. Finally, we are grateful to the Chief for Environmental Restoration at Beale Air Force Base in California and the Headquarters of the Air Combat Command at Langley Air Force Base in Virginia for providing and permitting us to use data from Beale Air Force Base. 


\section{TABLE OF CONTENTS}

Preface $\ldots \ldots \ldots \ldots \ldots \ldots \ldots \ldots \ldots \ldots \ldots \ldots \ldots \ldots \ldots \ldots \ldots \ldots \ldots \ldots \ldots \ldots \ldots$

Acknowledgment $\ldots \ldots \ldots \ldots \ldots \ldots \ldots \ldots \ldots \ldots \ldots \ldots \ldots \ldots \ldots \ldots \ldots$ iv

List of Tables $\ldots \ldots \ldots \ldots \ldots \ldots \ldots \ldots \ldots \ldots \ldots \ldots \ldots \ldots \ldots \ldots \ldots$

Abstract $\ldots \ldots \ldots \ldots \ldots \ldots \ldots \ldots \ldots \ldots \ldots \ldots \ldots \ldots \ldots \ldots \ldots \ldots \ldots \ldots \ldots \ldots \ldots$

Introduction $\ldots \ldots \ldots \ldots \ldots \ldots \ldots \ldots \ldots \ldots \ldots \ldots \ldots \ldots \ldots \ldots \ldots$

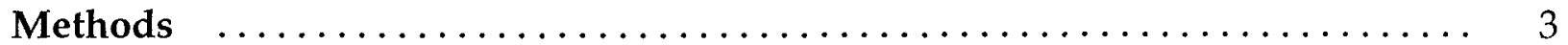

Exposure-pathway models $\ldots \ldots \ldots \ldots \ldots \ldots \ldots \ldots \ldots \ldots \ldots \ldots \ldots$

Cancer-risk model $\ldots \ldots \ldots \ldots \ldots \ldots \ldots \ldots \ldots \ldots \ldots \ldots \ldots \ldots \ldots$

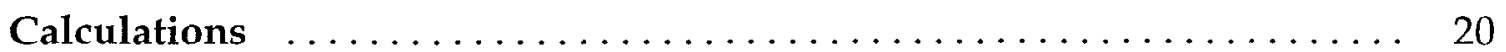

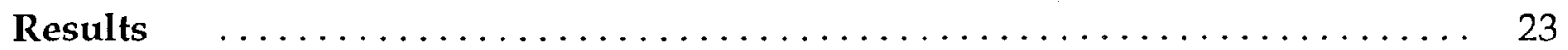

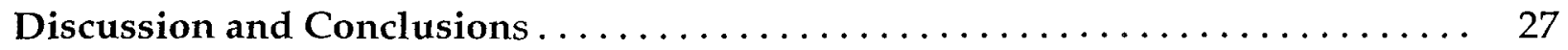

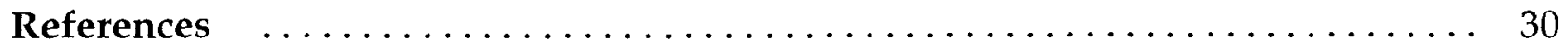

Appendix A: Glossary of Important Terms $\quad \ldots \ldots \ldots \ldots \ldots \ldots \ldots \ldots \ldots$ A-1

Appendix B: Further Explanations of (1) Additional Procedures Useful for Generating Several Different Input-Variate Distributions, and Corresponding Expected Values and Upper Bounds;

(2) The Approach for Deterministically Calculating Exposure and Traditional Risk-Related (Point) Estimators; and

(3) Methods for Estimating the Probability of Zero Additional Cases of Cancer $\left(P_{0}\right)$ 


\section{LIST OF TABLES}

Table 1. Inputs (not including regulatory default values) for obtaining cancer risk related estimators for multiple-pathway exposure to low-levels of trichloroethylene (TCE) concentrations in ground water at Beale Air Force Base in California ........... 10

Table 2. Inputs and corresponding regulatory default values applicable to a deterministic calculation of excess-lifetime cancer risk for a "reasonably maximum exposed" person $\left(\hat{R}_{\mathrm{RME}}\right) \ldots \ldots \ldots \ldots \ldots . \ldots 14$

Table 3. Lifetime excess cancer risk-related estimates for hypothetical residents adjacent to Beale Air Force Base in California, based on multiple-pathway (i.e., ingestion, inhalation, and dermal) exposures to ground water containing low-level concentrations of trichloroethylene (TCE) $\ldots \ldots \ldots \ldots \ldots \ldots \ldots \ldots \ldots \ldots \ldots \ldots \ldots$

Table 4. Population risk associated with multipathway exposures to ground water containing low-level concentrations of

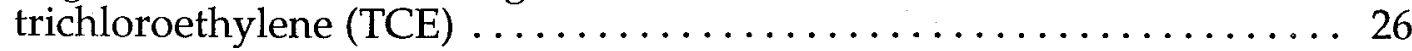

Table B-1. Weighting factor and age-specific ratios (Ings) of tapwater intakes to body weights [L/(kg-d)] for both sexes and all seasons for

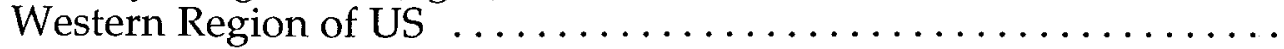

Table B-2. Weighting factor and age-specific ratios (Inhs) of inhalation rates to body weights $\left[\mathrm{m}^{3} /(\mathrm{kg}-\mathrm{d})\right.$ or $\left.\mathrm{L} /(\mathrm{kg}-\mathrm{d})\right]$ used for constructing respective composite and lifetime, time-weighted-average (TWA)

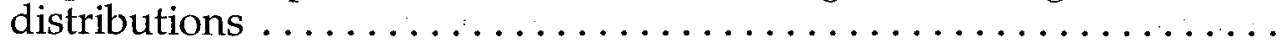

Table B-3. Weighting factor and age-specific ratios $(A s)$ of surface areas to to body weights $\left[\mathrm{cm}^{2} /(\mathrm{kg})\right]$ used for constructing respective composite and lifetime, time-weighted-average (TWA)

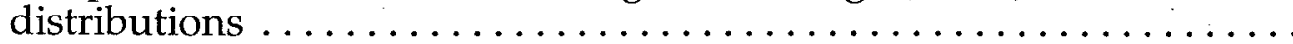

Table B-4. Input parameters, corresponding values, and respective resulting deterministically calculated exposure $\left(E_{\mathrm{Ing}}, E_{\mathrm{Inh}}, E_{\mathrm{Derm}}\right)$ and traditional risk-related $\hat{R}_{\mathrm{E}}$, "best" estimate; $\hat{R}_{\mathrm{RME}}$, risk to "reasonably maximum exposed" person; and $\hat{R}_{\text {High }}$, upper "conservative" bound) (point) estimators . . . . . . . . . . . . B-16 


\title{
Procedures for Addressing Uncertainty and Variability in Exposure to Characterize Potential Health Risk From Trichloroethylene Contaminated Groundwater at Beale Air Force Base in California
}

\begin{abstract}
Conservative deterministic, screening-level calculations of exposure and risk commonly are used in quantitative assessments of potential human-health consequences from contaminants in environmental media. However, these calculations generally are based on multiple upper-bound point estimates of input parameters, particularly for exposure attributes, and can therefore produce results for decision makers that actually overstate the need for costly remediation. Alternatively, a more informative and quantitative characterization of health risk can be obtained by quantifying uncertainty and variability in exposure. This process is illustrated in this report for a hypothetical population at a specific site at Beale Air Force Base in California, where there is trichloroethylene (TCE) contaminated ground water and a potential for its future residential use. When uncertainty and variability in exposure were addressed jointly for this case, the 95th-percentile upper-bound value of individual excess lifetime cancer risk was a factor approaching 10 lower than the most conservative deterministic estimate. Additionally, the probability of more than zero additional cases of cancer can be estimated, and in this case it is less than 0.5 for a hypothetical future residential population of up to 26,900 individuals present for any 7.6-y interval of a 70-y time period. Clearly, the results from application of this probabilistic approach can provide reasonable and equitable risk-acceptability criteria for a contaminated site.
\end{abstract}




\section{INTRODUCTION}

Quantitative assessments of the potential human health risks from contaminants present at hazardous-waste sites typically involve conservative deterministic, screeninglevel calculations of exposure and risk, often based on multiple upper-bound point estimates of input parameters. Because inherent conservatism in such estimates may result in highly inefficient strategies for site cleanup, there is growing interest in obtaining more informative and quantitative characterizations of human-health risk (NRC, 1994). Such assessments require quantitative methods to characterize joint uncertainty and interindividual variability (JUV) in estimated risk, based on both uncertainty and/or interindividual variability reflected in each input parameter (Bogen and Spear, 1987; NRC, 1994; Bogen, 1995). Uncertainty here refers to an absence of measurement data or incomplete knowledge; interindividual variability (or "variability") here refers to true differences or heterogeneity in an empirical, riskrelated characteristic (e.g., physiological differences) among individuals in a population (Bogen and Spear, 1987). Such probabilistic assessments can be resource intensive, but are generally appropriate at sites for which deterministic upper-bound calculations of risk overstate the need for costly remediation efforts. A glossary of the important terms associated with the JUV analysis procedures described in this report is presented in Appendix A.

This report provides a site-specific illustration of how JUV in exposure may be used to characterize risk. Results from such analyses provide an improved understanding of risk for decision makers, including estimates of the upper-bound risk to the average person in the population, the risk to an individual at the upper-bound of exposure, and the likelihood of additional cases of cancer in a population exposed to low-level site contaminants. The case study addresses inactive Landfill Site LF-13 on 
Beale Air Force Base in California, where groundwater contaminated with trichloroethylene (TCE) has moved beyond the site boundary. Consequently, soil-vapor extraction and air-stripping treatment of groundwater have been undertaken at Site LF-13 to remediate this situation (URSGWC, 1998). Specifically, these actions are designed to reduce to low-levels the concentrations of TCE (and other volatile organic compounds) in the ground water beneath Site LF-13. This is especially important because in this currently rural area of the Sacramento Valley of California, groundwater wells are the principle source of domestic-water supplies. Thus, elevated levels of TCE contamination, particularly, would prevent this water from being used for this purpose. Accordingly, this analysis focuses on potential risks attributable to a scenario that thcoretically could involve possible future domestic, residential uses of groundwater from beneath Site LF-13 that contains residual, low-level concentrations of TCE. This scenario is considered appropriate for addressing hypothetical residential populations of different sizes that might eventually occupy lands adjacent to the site. The measurements of TCE-concentration used for this analysis were those obtained in 1997 from the groundwater monitoring well on Site LF-13 near the possible location of a future groundwater extraction and distribution system (Purrier, 1997). A characterization of JUV in risk is performed, and corresponding estimates of the expected number of additional cancer cases and the probability of greater than zero additional cases for specified populations are obtained. Finally, risk estimators from the JUV approach are compared to those calculated using the traditional framework for computing risk deterministically. 


\section{METHODS}

The procedures utilized here are ones designed to address JUV in the context of risk characterization (Bogen and Spear, 1987; NRC, 1994; Bogen, 1995). For TCE in groundwater at Site LF-13 on Beale Air Force Base in California, total risk, $R$, is defined as the increased lifetime probability of cancer for an individual attributable to TCE exposure from three pathways: direct ingestion, $E_{\text {Ing, }}$ of TCE-contaminated groundwater; dermal absorption, $E_{\text {Derm }}$, of TCE while showering or bathing; and inhalation, $E_{\text {Inh }}$, of TCE volatilized from water to household air. For volatile organic compounds such as TCE, these three pathways typically are the most significant contributors to its total daily dose (or intake).

This document uses a consistent approach that conforms with previous application of JUV notation (see also the glossary of important terms appearing in Appendix A): an overbar (i.e., - ) is used to denote expectation with respect to heterogeneous parameters only, and angle brackets (i.e., \langle\rangle$)$ to denote expectation with respect to uncertain parameters only (Bogen and Spear, 1987; NRC, 1994; Bogen, 1995). A tilde (i.e., ) appearing over a term shall be used to denote a sample mean of empirical values.

\section{Exposure-Pathway Models}

The three equations described next are used to model the most important human-exposure pathways for TCE in ground water. These equations are consistent with those described by USEPA (1989) and also CalEPA/DTSC (1994) for modeling these exposure pathways. 
Exposure to TCE from direct ingestion of groundwater was calculated using

Eq. 1.

$$
E_{\text {Ing }}=\operatorname{Ing} \times E D \times \frac{E F}{A T} \times C_{\mathrm{w}},
$$

where

$E_{\text {Ing }}=$ TCE-exposure (intake) resulting from direct ingestion of contaminated ground water $[\mathrm{mg} /(\mathrm{kg}-\mathrm{d})]$;

Ing = daily water ingestion rate per unit body weight $[\mathrm{L} /(\mathrm{kg}-\mathrm{d})]$;

$E D=$ exposure duration, also referred to as time of residence $(\mathrm{y})$;

$E F=\operatorname{exposure}$ frequency $(\mathrm{d} / \mathrm{y}) ;$

$A T=$ averaging time corresponding to a 70-y lifetime of exposure (d); and

$C_{\mathrm{w}}=$ TCE concentration in ground water $(\mathrm{mg} / \mathrm{L})$.

TCE can volatilize to indoor air from water used in showering, bathing, and by the use of toilets, dishwashers, washing machines, and cooking. Inhalation exposure to TCE was calculated by the procedure of McKone and Bogen (1992) for estimating uptake of a volatile contaminant in tap water for a hypothetical four-occupant household. That approach utilizes contaminant water-to-air transfer factors in conjunction with the model developed by Fisk et al. (1987) to estimate householdcompartment concentrations of volatile contaminants in air. Therefore, the resulting exposure to TCE in indoor air was derived using Eq. 2.

$$
\begin{aligned}
E_{\text {Inh }}= & \operatorname{Inh} \times \frac{\left[\left(\frac{W_{\mathrm{sh}} \times \phi_{\text {TCE-sh }}}{A E_{\mathrm{sh}}} \times E T_{\mathrm{sh}}\right)+\left(\frac{W_{\mathrm{b}} \times \phi_{\mathrm{TCE}-\mathrm{sh}}}{A E_{\mathrm{b}}} \times E T_{\mathrm{b}}\right)+\left(\frac{W_{\mathrm{h}} \times \phi_{\mathrm{TCE}-\mathrm{h}}}{A E_{\mathrm{h}}} \times E T_{\mathrm{h}}\right)\right]}{D} \times \\
& E D \times \frac{E F}{A T} \times C_{\mathrm{w}}
\end{aligned}
$$


where

$E_{\mathrm{Inh}}=$ TCE-exposure (intake) resulting from inhalation of TCE volatilized into indoor air from contaminated ground water used for domestic purposes $[\mathrm{mg} /(\mathrm{kg}-\mathrm{d})]$;

Inh = daily inhalation rate per unit body weight $\left[\mathrm{m}^{3} /(\mathrm{kg}-\mathrm{d})\right]$;

$W_{\mathrm{sh}}=$ water-useage rate per person for shower $(\mathrm{L} / \mathrm{h})[$ and also for bathroom, $\left.W_{\mathrm{b}}(\mathrm{L} / \mathrm{h})\right]$;

$W_{\mathrm{h}}=$ water-useage rate for all household activities $(\mathrm{L} / \mathrm{h}) ;$

$\phi_{\text {TCE-sh }}=$ water-to-air transfer efficiency of TCE in the shower (dimensionless);

$\phi_{\mathrm{TCE}-\mathrm{h}}=$ water-to-air transfer efficiency of TCE in the house (dimensionless), and equal to $\phi_{\text {TCE-sh }} \times 0.54 / 0.70$ (where the fraction is the ratio of radon transfer in the shower to radon transfer in the house as reported by McKone and Bogen, $1992)$, with $\phi_{\mathrm{TCE}-\mathrm{h}}$ modeled as statistically independent of $\phi_{\mathrm{TCE}-\mathrm{sh}}$;

$A E_{\text {sh }}=$ air-exchange rate in the shower or bath stall $\left(\mathrm{m}^{3} / \mathrm{h}\right)$;

$A E_{\mathrm{b}}=$ air-exchange rate in the bathroom $\left(\mathrm{m}^{3} / \mathrm{h}\right) ;$

$A E_{\mathrm{h}}=$ air-exchange rate in the house $\left(\mathrm{m}^{3} / \mathrm{h}\right)$;

$E T_{\mathrm{sh}}=$ exposure time in showering or bathing $(\mathrm{h} / \mathrm{d}) ;$

$E T_{\mathrm{b}}=$ exposure time in bathroom $(\mathrm{h} / \mathrm{d}) ;$

$E T_{\mathrm{h}}=$ exposure time in house $(\mathrm{h} / \mathrm{d}) ;$

$D$ = averaging time for daily water use $(24 \mathrm{~h} / \mathrm{d})$;

$E D=$ exposure duration, also referred to as time of residence $(\mathrm{y}) ;$

$E F=$ exposure frequency $(\mathrm{d} / \mathrm{y}) ;$

$A T=$ averaging time corresponding to a 70-y lifetime of exposure (d); and

$C_{\mathrm{w}}=\mathrm{TCE}$ concentration in ground water $(\mathrm{mg} / \mathrm{L})$.

Dermal uptake of TCE while showering or bathing is based on the model of Brown et al. (1984) and was calculated from the relationship shown in Eq. 3.

$$
E_{\text {Derm }}=A \times f_{\mathrm{s}} \times k_{\mathrm{p}} \times E T_{\mathrm{sh}} \times \mathrm{cf} \times E D \times \frac{E F}{A T} \times\left[C_{\mathrm{w}} \times\left(1-\frac{\phi_{\mathrm{TCE}-\mathrm{sh}}}{2}\right)\right],
$$


where

$E_{\text {Derm }}=$ TCE-exposure (intake) resulting from dermal uptake of TCE while showering or bathing [mg/(kg-d)];

$A=$ surface area of skin per unit body weight $\left(\mathrm{cm}^{2} / \mathrm{kg}\right) ;$

$f_{\mathrm{s}}=$ fraction of total skin surface that is in contact with water during showering or bathing (dimensionless);

$k_{\mathrm{p}}=$ dermal permeability rate of TCE from dilute aqueous solutions $(\mathrm{cm} / \mathrm{h}) ;$

$E T_{\mathrm{sh}}=$ time spent showering or bathing $(\mathrm{h} / \mathrm{d})$;

cf $=$ conversion factor $\left(10^{-3} \mathrm{~L} / \mathrm{cm}^{3}\right)$

$E D=$ exposure duration, also referred to as time of residence (y);

$E F=$ exposure frequency $(\mathrm{d} / \mathrm{y}) ;$

$A T=$ averaging time corresponding to a 70-y lifetime of exposure (d); and

$C_{\mathrm{w}}=$ TCE concentration in ground water $(\mathrm{mg} / \mathrm{L}) ;$

$\phi_{\text {TCE-sh }}=$ water-to-air transfer efficiency of TCE in the shower (dimensionless);

Three concentration measurements of TCE were obtained in 1997 from a monitoring well at Site LF-13 on Beale Air Force Base (Purrier, 1997). This monitoring well is used for evaluating remediation efforts and is located in the immediate vicinity of the site of an extraction well that hypothetically could eventually supply ground water for domestic purposes to possible future residences in the surrounding area. Because soil-vapor extraction and air-stripping treatment of the ground water have been taking place at Site LF-13 to reduce the concentration of TCE to low-levels in the ground water (URSGWC, 1998), it is assumed that there are now no real differences between the three reported sample measurements and that the TCE concentration in the ground water is unlikely to be changing in time. On the basis of these assumptions (which are made for purposes of this illustration and require validation) and because there will be mixing and blending of the ground water during its extraction and 
distribution, a hypothetical resident using such ground water domestically is likely to be exposed to the mean concentration. Accordingly, the uncertain mean TCE concentration in ground water was modeled as

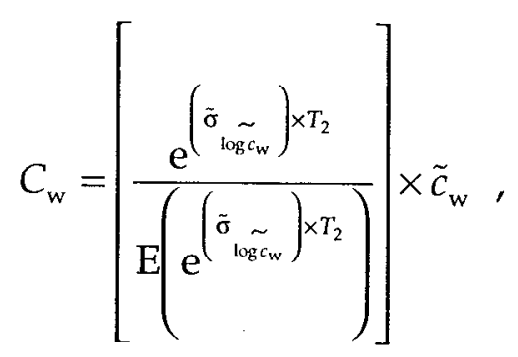

where

$C_{\mathrm{w}}=$ mean TCE concentration $(\mathrm{mg} / \mathrm{L})$, where uncertainty in $\log c_{\mathrm{w}}$ is assumed to be T-distributed with two degrees of freedom;

$\left\langle C_{\mathrm{w}}\right\rangle \equiv \tilde{\mathrm{c}}_{\mathrm{w}}=$ the sample mcan of the three $c_{\mathrm{w}}$ measures (Purrier, 1997);

$\log c_{\mathrm{w}}=$ sample mean of the three $\log c_{\mathrm{w}}$ measures;

$\tilde{\sigma}_{\log c_{w}}=$ sample standard deviation of the three $\log c_{\mathrm{w}}$ measures;

$\tilde{\sigma}_{\log c_{w}}=$ standard deviation of the sample mean of $\log c_{w}$, where $\tilde{\sigma}_{\log c_{w}}=\frac{\tilde{\sigma}_{\log c_{w}}}{\sqrt{3}}=0.1295 ;$ and

$T_{2} \quad=$ variate distributed as Student's $\mathrm{T}$ with two degrees of freedom (see Appendix $B$ for further explanation useful for constructing this distribution).

The expected-value term in Eq. 5, $\mathrm{E}\left(\mathrm{e}^{\left({ }^{\tilde{\sigma}} \tilde{\log }_{c_{\infty}}\right) \times T_{2}}\right)$, was determined to be 1.0812, based on a Monte-Carlo simulation involving 2000 trials. The bracketed term in Eq. 5 thus reflects a $\log -\mathrm{T}_{2}$-distributed variate normalized to have an expected value equal to one.

Inter-household variability in water-to-air transfer efficiency of TCE in shower water ( $\phi_{\text {TCE-Sh }}$, which is a dimensionless term) was modeled based on 14 experimental 
measures involving showers running water at $\geq 30{ }^{\circ} \mathrm{C}$ summarized by Corsi and Howard (1998). It was assumed that these measures reflect the effects on TCE transfer of variable conditions that may pertain to each household at risk over the course of any residential duration. Effective residential TCE water-to-air transfer efficiency, $\phi_{\text {TCE-sh }}$ was therefore estimated as the mean value of the reported measures (0.76), and variability in $\phi_{\text {TCE-sh }}$ was modeled by the relation

$$
\phi_{\mathrm{TCE}-\mathrm{sh}}=0.76+\left(0.029 \times T_{\phi_{\mathrm{TCE}-\mathrm{sh}}}\right),
$$

where 0.029 is the standard deviation of the mean of the measured values [which ranged from as much as 0.97 (for a $45^{\circ} \mathrm{C}$ water temperature) to as low as 0.61 (for a $33^{\circ} \mathrm{C}$ water temperature)], and $T_{\phi_{\text {TCE:sh }}}$ is a variate that has a Student's $T$ distribution with 13 degrees of freedom (see Appendix B for further explanation useful for constructing this distribution).

The term $\left[C_{w} \times\left(1-\frac{\phi_{\text {TCE-sh }}}{2}\right)\right]$ in Eq. 3 estimates the concentration of TCE in the water contacting the skin during showering, based on the assumption that TCE volatilization is approximately linearly proportional to the vertical distance water has fallen from the showerhead to the floor (Giardino et al., 1992), and that during showering the body contacts the water about half the distance between the showerhead and the floor. The term in Eq. 3 is also applicable to a bathing scenario, because approximately 30 to $47 \%$ of TCE volatilizes during bathtub-filling prior to bathing (see McKone, 1987).

Table 1 presents the input parameters identified or implied in Eqs. 1-3, but does not include the regulatory default values for such inputs, which appear in Table 2 . In 
Table 1, distributions for parameters are identified as representing either uncertainty or variability (heterogeneity) and corresponding distribution types are also listed. The exposure-model parameters treated as constants in this assessment are EF and $A T$. Other input variates were assumed to be distributed as summarized in Table 1 and as further described below. As indicated in Table 1, with the exception of the $C_{\mathrm{w}}$ and $f_{\mathrm{m}}$ variates, which are considered uncertain, all distributed input variates were assumed to be heterogeneous (i.e., to reflect interindividual variability).

The exposure duration $(E D)$ term, in Eqs. 1-3 denotes household residence time in the area that would be supplied with the contaminated ground water for domestic purposes. Because ED should account for households moving into and out of the water-supply area, it is modeled to reflect nonlinear JUV. The procedure used to obtain $\overline{E D}$ and $\langle E D\rangle$ distributions (and also a "rough," but conservative, approximation of the $95^{\text {th }}$-percentile upper-bound value, $\hat{E D}$, of the cumulative probability distribution reflecting variability in exposure duration) adapts the Israeli and Nelson (1992) model of variability in the time of residence for households in the Western Region of the US. Specifically, this model defines the fraction $R(t)$ of households living in the same residence for a total of $t$ years or more for the Western Region [see Eq. 12 and the corresponding parameter values in Table II of Israeli and Nelson (1992)].* According to this model,

$$
l(s)=\frac{-\mathrm{d}[\log R(s)]}{\mathrm{d} s}
$$

\footnotetext{
* Note that we retain here the Israeli and Nelson (1992) notation for the fraction $R(t)$ as a function of time, which should not be confused with risk, $R$, defined (independent of time) in Eq. 13 of this report.
} 
Table 1. Inputs (not including regulatory default values; see Table 2) for obtaining cancer risk-related estimators (see Table 3) for multiple-pathway exposure to low-levels of trichloroethylene (TCE) concentrations in ground water at Beale Air Force Base in California.

\begin{tabular}{|c|c|c|c|c|c|c|c|c|c|c|c|c|}
\hline \multirow[b]{2}{*}{$\begin{array}{l}\text { Variate } \\
\text { (units) }\end{array}$} & \multirow[b]{2}{*}{ Symbol } & \multicolumn{2}{|c|}{ Distribution } & \multicolumn{2}{|c|}{ Range } & \multicolumn{2}{|c|}{ Arithmetic } & \multicolumn{2}{|c|}{ Geometric } & \multicolumn{2}{|c|}{ Percentile } & \multirow[b]{2}{*}{ Source of data } \\
\hline & & Represents & Type $^{a}$ & Min. & Max. & Mean & $\begin{array}{l}\text { Stnd. } \\
\text { Dev. }\end{array}$ & Mean & $\begin{array}{l}\text { Stnd. } \\
\text { Dev. }\end{array}$ & 5 th & 95th & \\
\hline $\begin{array}{l}\text { Mean TCE } \\
\text { concentration in } \\
\text { water }(\mathrm{mg} / \mathrm{L})\end{array}$ & $C_{w}$ & Uncertainty & $\log -T_{2}$ & & & 0.0223 & & & & & 0.0301 & Purrier (1997) \\
\hline $\begin{array}{l}\text { Fraction of } \\
\text { emigrant } \\
\text { residents } \\
\text { moving out } \\
\text { of a local } \\
\text { water-supply } \\
\text { district in } \\
\text { western US } \\
\text { (dimensionless) }\end{array}$ & $f_{\mathrm{m}}$ & Uncertainty & Tri & $\frac{1}{3}$ & 1 & $\frac{2}{3}$ & $\sqrt{\frac{1}{54}}$ & & & $\begin{array}{l}0.439 \\
\left(=f_{\mathrm{m}}^{*}\right)\end{array}$ & & $\begin{array}{l}\text { US Census } \\
\text { Bureau (1997) }\end{array}$ \\
\hline $\begin{array}{l}\text { Cumulative } \\
\text { distribution } \\
\text { function for } \\
\text { total residence } \\
\text { time in the } \\
\text { western US } \leq t \\
\text { (y) }\end{array}$ & $1-R(t)$ & Variability & $\mathrm{E}$ & & & 3.49 & & & $\therefore$ & & & $\begin{array}{l}\text { Israeli and } \\
\text { Nelson (1992) }\end{array}$ \\
\hline $\begin{array}{l}\text { Approximate } \\
\text { upper-bound } \\
\text { residence } \\
\text { duration (used } \\
\text { to calculate } \\
\hat{R}_{\text {High }} \text { ) }\end{array}$ & $\begin{array}{l}\hat{E D}= \\
{\left[\begin{array}{l}1- \\
R(t)^{f_{\mathrm{m}}}\end{array}\right]}\end{array}$ & Variability & $E$ & & & & & & & & 55.3 & $\begin{array}{l}\text { See Eqs. } 8 \text { and } \\
11\end{array}$ \\
\hline $\begin{array}{l}\text { Ingestion rate } \\
\text { for western } \\
\text { region of US } \\
{[\mathrm{L} /(\mathrm{kg}-\mathrm{d})]}\end{array}$ & Ing & Variability & $\mathrm{LN}$ & & & 0.0242 & 0.0170 & 0.0198 & 1.88 & & 0.0399 & $\begin{array}{l}\text { Ershow and } \\
\text { Cantor }(1989)^{\mathrm{b}}\end{array}$ \\
\hline
\end{tabular}




\begin{tabular}{|c|c|c|c|c|c|c|c|c|c|c|c|c|}
\hline \multirow[b]{2}{*}{$\begin{array}{l}\text { Variate } \\
\text { (units) }\end{array}$} & \multirow[b]{2}{*}{ Symbol } & \multicolumn{2}{|c|}{ Distribution } & \multicolumn{2}{|c|}{ Range } & \multicolumn{2}{|c|}{ Arithmetic } & \multicolumn{2}{|c|}{ Geometric } & \multicolumn{2}{|c|}{ Percentile } & \multirow[b]{2}{*}{ Source of data } \\
\hline & & Represents & Type $^{a}$ & Min. & Max. & Mean & $\begin{array}{l}\text { Stnd. } \\
\text { Dev. }\end{array}$ & Mean & $\begin{array}{l}\text { Stnd. } \\
\text { Dev. }\end{array}$ & 5 th & 95th & \\
\hline $\begin{array}{l}\text { Inhalation rate } \\
{\left[\mathrm{m}^{3} /(\mathrm{kg} \mathrm{d})\right]}\end{array}$ & $\operatorname{Inh}$ & Variability & $E$ & & & 0.264 & & & & & 0.363 & $\begin{array}{l}\text { OEHHA (1996) } \\
\text { and Marty } \\
\text { (1998); and } \\
\text { US Census } \\
\text { Bureau }(1998)^{\text {b }}\end{array}$ \\
\hline $\begin{array}{l}\text { Shower (and } \\
\text { also bathroom) } \\
\text { water-use } \\
\text { rate(s) }(\mathrm{L} / \mathrm{h})\end{array}$ & $\begin{array}{l}W_{\text {sh }} \\
\text { (and } \\
\left.W_{b}\right)\end{array}$ & Variability & LN & & & 480 & 160 & 455 & 1.38 & & 777 & $\begin{array}{l}\text { McKone and } \\
\text { Bogen (1992), } \\
\text { based on James } \\
\text { and Knuiman } \\
\text { (1987) }\end{array}$ \\
\hline $\begin{array}{l}\text { Household } \\
\text { water-use rate } \\
(\mathrm{L} / \mathrm{h})\end{array}$ & $W_{\mathrm{h}}$ & Variability & $\mathrm{LN}$ & & & 42.0 & 15.0 & 40.0 & 1.41 & & 69.9 & $\begin{array}{l}\text { McKone and } \\
\text { Bogen (1992), } \\
\text { based on James } \\
\text { and Knuiman } \\
\text { (1987) }\end{array}$ \\
\hline $\begin{array}{l}\text { Normalized } \\
\text { mean } \\
\text { water-to-air } \\
\text { transfer } \\
\text { efficiency } \\
\text { for TCE } \\
\text { (dimensionless) }\end{array}$ & $T_{\phi_{\text {TCE-Sh }}}$ & Variability & $\mathrm{T}_{13}$ & & & 0 & & & & & 1.771 & $\begin{array}{l}\text { Corsi and } \\
\text { Howard (1998) }\end{array}$ \\
\hline $\begin{array}{l}\text { Air-exchange } \\
\text { rate for shower } \\
\left(\mathrm{m}^{3} / \mathrm{h}\right)\end{array}$ & $A E_{\mathrm{sh}}$ & Variability & $\mathrm{U}$ & 4.0 & 20.0 & $9.94^{c}$ & & & & $4.82^{c}$ & & $\begin{array}{l}\text { McKone and } \\
\text { Bogen (1992) }\end{array}$ \\
\hline
\end{tabular}


Table 1. (continued)

\begin{tabular}{|c|c|c|c|c|c|c|c|c|c|c|c|c|}
\hline \multirow[b]{2}{*}{$\begin{array}{l}\text { Variate } \\
\text { (units) }\end{array}$} & \multirow[b]{2}{*}{ Symbol } & \multicolumn{2}{|c|}{ Distribution } & \multicolumn{2}{|c|}{ Range } & \multicolumn{2}{|c|}{ Arithmetic } & \multicolumn{2}{|c|}{ Geometric } & \multicolumn{2}{|c|}{ Percentile } & \multirow[b]{2}{*}{ Source of data } \\
\hline & & Represents & Type $^{\mathrm{a}}$ & Min. & Max. & Mean & $\begin{array}{l}\text { Stnd. } \\
\text { Dev. }\end{array}$ & Mean & $\begin{array}{l}\text { Stnd. } \\
\text { Dev. }\end{array}$ & 5 th & 95th & \\
\hline $\begin{array}{l}\text { Air-exchange } \\
\text { rate for } \\
\text { bathroom } \\
\left(\mathrm{m}^{3} / \mathrm{h}\right)\end{array}$ & $A E_{\mathrm{b}}$ & Variability & $\mathrm{U}$ & 10.0 & 100.0 & $39.1^{c}$ & & & & $14.6^{c}$ & & $\begin{array}{l}\text { McKone and } \\
\text { Bogen (1992) }\end{array}$ \\
\hline $\begin{array}{l}\text { Air-exchange } \\
\text { rate for house } \\
\left(\mathrm{m}^{3} / \mathrm{h}\right)\end{array}$ & $A E_{\mathrm{h}}$ & Variability & $\mathrm{U}$ & 300 & 1200 & $649^{c}$ & & & & $344^{c}$ & & $\begin{array}{l}\text { McKone and } \\
\text { Bogen (1992) }\end{array}$ \\
\hline $\begin{array}{l}\text { Exposure time } \\
\text { in shower }(\mathrm{h} / \mathrm{d})\end{array}$ & $E T_{\text {sh }}$ & Variability & $\mathrm{LN}$ & & & 0.129 & 0.052 & 0.120 & 1.47 & & 0.226 & $\begin{array}{l}\text { Burmaster } \\
(1998)\end{array}$ \\
\hline $\begin{array}{l}\text { Exposure time } \\
\text { in bathroom } \\
(\mathrm{h} / \mathrm{d})\end{array}$ & $E T_{\mathrm{b}}$ & Variability & $\mathrm{LN}$ & & & 0.330 & 0.220 & 0.274 & 1.83 & & 0.744 & $\begin{array}{l}\text { McKone and } \\
\text { Bogen (1992) }\end{array}$ \\
\hline $\begin{array}{l}\text { Exposure time } \\
\text { in house }(\mathrm{h} / \mathrm{d})\end{array}$ & $E T_{\mathrm{h}}$ & Variability & $\mathrm{U}$ & 8.0 & 20.0 & 14.0 & & & & & 19.4 & $\begin{array}{l}\text { McKone and } \\
\text { Bogen (1992) }\end{array}$ \\
\hline $\begin{array}{l}\text { Surface area per } \\
\text { unit body } \\
\text { weight }\left(\mathrm{cm}^{2} / \mathrm{kg}\right)\end{array}$ & $A$ & Variability & $\mathrm{E}$ & & & 326 & & & & & 373 & $\begin{array}{l}\text { Phillips et al. } \\
\text { (1993); and } \\
\text { US Census } \\
\text { Bureau (1998) }^{\mathrm{b}}\end{array}$ \\
\hline $\begin{array}{l}\text { Fraction of skin } \\
\text { exposed in } \\
\text { shower or bath } \\
\text { (dimensionless) }\end{array}$ & $f_{s}$ & Variability & $\mathrm{U}$ & 0.40 & 0.90 & 0.65 & & & & & 0.875 & $\begin{array}{l}\text { McKone and } \\
\text { Bogen (1992) }\end{array}$ \\
\hline $\begin{array}{l}\text { Skin- } \\
\text { permeability } \\
\text { coefficient } \\
(\mathrm{cm} / \mathrm{h})\end{array}$ & $k_{\mathrm{p}}$ & Variability & $N$ & & & 0.263 & 0.018 & & & & 0.293 & $\begin{array}{l}\text { Bogen et al. } \\
(1998)\end{array}$ \\
\hline
\end{tabular}


Table 1. (continued)

\begin{tabular}{|c|c|c|c|c|c|c|c|c|c|c|c|c|}
\hline \multirow[b]{2}{*}{$\begin{array}{l}\text { Variate } \\
\text { (units) }\end{array}$} & \multirow[b]{2}{*}{ Symbol } & \multicolumn{2}{|c|}{ Distribution } & \multicolumn{2}{|c|}{ Range } & \multicolumn{2}{|c|}{ Arithmetic } & \multicolumn{2}{|c|}{ Geometric } & \multicolumn{2}{|c|}{ Percentile } & \multirow[b]{2}{*}{ Source of data } \\
\hline & & Represents & Type $^{a}$ & Min. & Max. & Mean & $\begin{array}{l}\text { Stnd. } \\
\text { Dev. }\end{array}$ & Mean & $\begin{array}{l}\text { Stnd. } \\
\text { Dev. }\end{array}$ & 5 th & 95th & \\
\hline $\begin{array}{l}\text { Cancer slope } \\
\text { factor applicable } \\
\text { to both } \\
\text { ingestion and } \\
\text { dermal } \\
\text { exposures } \\
\{R /[\mathrm{mg} /(\mathrm{kg}-\mathrm{d})]\}\end{array}$ & $\begin{array}{l}C S F_{\text {Ing }} \\
\text { (and } \\
\text { also } \\
C S F_{\text {Derm }} \text { ) }\end{array}$ & $\begin{array}{l}\text { Not } \\
\text { applicable }\end{array}$ & $\mathrm{C}$ & & & & & & & & 0.015 & CalEPA (1996) \\
\hline $\begin{array}{l}\text { Cancer slope } \\
\text { factor applicable } \\
\text { to inhalation } \\
\text { exposure } \\
\{\mathrm{R} /[\mathrm{mg} /(\mathrm{kg}-\mathrm{d})]\}\end{array}$ & $C S F_{\text {Inh }}$ & $\begin{array}{l}\text { Not } \\
\text { applicable }\end{array}$ & $\mathrm{C}$ & & & & & & & & 0.010 & CalEPA (1996) \\
\hline $\begin{array}{l}\text { Averaging } \\
\text { time for } 70-y \\
\text { lifespan (d) }\end{array}$ & $A T$ & $\begin{array}{l}\text { Not } \\
\text { applicable }\end{array}$ & $C$ & & 25,550 & & & & & & & $\begin{array}{l}\text { USEPA } \\
\text { Region } 9 \text { (1998) } \\
\text { and USEPA } \\
(1989)\end{array}$ \\
\hline $\begin{array}{l}\text { Exposure } \\
\text { frequency } \\
\text { (upper-bound } \\
\text { value; } d / y \text { ) }\end{array}$ & $E F$ & $\begin{array}{l}\text { Not } \\
\text { applicable }\end{array}$ & $\mathrm{C}$ & & 350 & & & & & & & $\begin{array}{l}\text { USEPA } \\
\text { Region } 9 \text { (1998) } \\
\text { and USEPA } \\
(1991)\end{array}$ \\
\hline
\end{tabular}

a Distribution types: $C=$ constant; $E=$ empirical (or fitted); $L N=$ lognormal; $N=$ normal; $T_{d f}=$ Student's $T$ with df equal to degrees of freedom; log- $\mathrm{T}_{\mathrm{df}}=$ exponentiated $\mathrm{T}_{\mathrm{df}}$ distribution; $\mathrm{Tri}=$ triangular, $\mathrm{U}=$ uniform.

${ }^{b}$ Upper-bound $\left(95^{\text {th }}\right.$ percentile) values for lifetime, time-weighted-average quantities calculated using information from the cited references (see Methods).

'Mean and corresponding 5-percentile values associated with each air-exchange $(A E)$ rates were obtained from the inverseuniform distribution $(1 / \mathrm{U})$ that was constructed from a Monte-Carlo simulation, involving 2,000 trials, of the uniform distribution. Thus, values reported in units of the data are the harmonic mean and the inverse of the $95^{\text {th }}$ percentile of $1 / \mathrm{U}$. This was done so that expected values of risk-related estimators could be calculated using the corresponding exact expressions (which include $A E$ values appearing as denominators-see Eq. 2). 
Table 2. Inputs and corresponding regulatory default values applicable to a deterministic calculation of excess-lifetime cancer risk for a "reasonably maximum exposed" person $\left(\hat{R}_{\mathrm{RME}}\right)$.

\begin{tabular}{|c|c|c|}
\hline Variate (units) & Value & Reference \\
\hline Ingestion rate $(\mathrm{L} / \mathrm{d})$ & 2.0 & $\begin{array}{l}\text { USEPA Region } 9 \text { (1998); } \\
\text { USEPA (1989) }\end{array}$ \\
\hline Body weight (kg) & 70.0 & $\begin{array}{l}\text { USEPA Region } 9 \text { (1998); } \\
\text { USEPA (1989) }\end{array}$ \\
\hline Inhalation rate $\left(\mathrm{m}^{3} / \mathrm{d}\right)$ & 20.0 & $\begin{array}{l}\text { USEPA Region } 9 \text { (1998); } \\
\text { USEPA (1989) }\end{array}$ \\
\hline Exposure time in house $(\mathrm{h} / \mathrm{d})$ & 16.4 & $\begin{array}{l}\text { USEPA Region } 9 \text { (1998); } \\
\text { Tsang and Klepeis (1996) }\end{array}$ \\
\hline Shower duration $(\mathrm{h} / \mathrm{d})$ & 0.13 & $\begin{array}{l}\text { USEPA (1997); James and } \\
\text { Knuiman (1987) }\end{array}$ \\
\hline Skin-surface area $\left(\mathrm{cm}^{2}\right)$ & $23,000.0$ & CalEPA/DTSC (1994) \\
\hline $\begin{array}{l}\text { Residential-exposure } \\
\text { duration }(y)\end{array}$ & 30.0 & $\begin{array}{l}\text { USEPA Region } 9 \text { (1998); } \\
\text { USEPA (1989) }\end{array}$ \\
\hline $\begin{array}{l}\text { Residential-exposure } \\
\text { frequency }(y)\end{array}$ & 350.0 & $\begin{array}{l}\text { USEPA Region } 9 \text { (1998); } \\
\text { USEPA (1991) }\end{array}$ \\
\hline Averaging time $(\mathrm{d})$ & $25,550.0$ & $\begin{array}{l}\text { USEPA Region } 9 \text { (1998); } \\
\text { USEPA (1989) }\end{array}$ \\
\hline $\begin{array}{l}\text { Ingestion (and used for dermal) } \\
\text { cancer-slope factor }\left(C S F_{\text {Ing }}\right) \\
\{\text { Risk/[mg/(kg d)]\} }\end{array}$ & 0.015 & CalEPA (1996) \\
\hline $\begin{array}{l}\text { Inhalation cancer-slope factor } \\
\left(C S F_{\text {Inh }}\right)\{\text { Risk } /[\mathrm{mg} /(\mathrm{kg} \mathrm{d})]\}\end{array}$ & 0.01 & CalEPA (1996) \\
\hline
\end{tabular}

a Characterizing risk for the "reasonable maximum exposure" case involves combining upper-bound and mid-range factors so that a conservative estimate (i.e., above the average) results that is within the range of reasonable possibilities, and is not the worst-possible case (USEPA, 1989 and 1991). The inputs to the $\hat{R}_{\mathrm{RME}}$ identified here are consistent with this goal. Specifically, the inputs and corresponding regulatory default values shown are used. Where default values are not given (and cannot be obtained from those shown) for uncertain variates (e.g., TCE concentration in water) the expected value for that input is used (see Table 1). Similarly, in the absence of default values for heterogeneous variates (e.g., water-use rates) the $95 \%$-tile value for that input is used (see Table 1); unless the heterogeneous variate was in the denominator of an equation (e.g., air-exchange rates), and then the $5 \%$-tile value is used (sce Table 1 and also footnote cof Table 1). 
where $0 £ s £ t$ and $l(s)$ is the rate of household moves, implying that $R(t)$ is modeled as a single "compartment" with loss rate $l(s)$ for $0 £ s £ t$, i.e., as

$$
R(t)=R_{0} \mathrm{e}^{-\int_{0}^{t} t(s) \mathrm{d} s},
$$

where $R_{0}=R(0)=1$, and $R(\infty)=0$. Now, let $f_{\mathrm{m}}$ be the fraction of household moves that are "effective", because they involve moves out of an area of concern (in our case, a hypothetical future water-supply district). Thus,

$$
R_{f_{\mathrm{m}}}(t)=\mathrm{e}^{-\int_{0}^{t} t(s) \times f_{\mathrm{m}} \mathrm{d} s}=[R(t)]^{f_{\mathrm{m}}},
$$

where $R(t)$ is heterogeneous and $f_{\mathrm{m}}$ is uncertain. Based on geographic mobility data reported by the US Census Bureau (1997), about $\frac{2}{3}$ of all US moves are within the same county. We assume that these moves include an uncertain fraction $\left(1-f_{\mathrm{m}}\right)$ that are within the same water-supply district, and that $\left(1-f_{\mathrm{m}}\right)$ is triangularly distributed between 0 and $\frac{2}{3}$ with a mode at $\frac{1}{3}$, which is consistent with data indicating that many households move small distances within corresponding local areas (ARC, 1999; and Duke-Williams, 1999). Thus, as indicated in Table 1 we assume $f_{\mathrm{m}}$ is triangularly distributed between $\frac{1}{3}$ and 1 with a mode at $\frac{2}{3}$.

The population-average value of total residence time, $\overline{E D}$, with respect to variability in $E D$, is defined by Israeli and Nelson (1992) as

$$
\overline{E D}=\int_{0}^{\infty} R(t) \mathrm{d} t
$$

(i.e., conditional on $f_{\mathrm{m}}=1$ ). It follows that for any value of $f_{\mathrm{m}^{\prime}}$ the corresponding population-average value of uncertain total residence time is specified by 


$$
\overline{E D}=\int_{0}^{\infty} R_{f_{\mathrm{m}}}(t) \mathrm{d} t=\int_{0}^{\infty}[R(t)]^{f_{\mathrm{ni}}} \mathrm{d} t
$$

in which uncertainty in $f_{\mathrm{m}}$ was discussed above.

The cumulative probability distribution reflecting variability in total time of residence, $t$, is defined as $1-R(t)$, in the model of Israeli and Nelson (1992; see their Eq. 4). The corresponding definition of variability in expected $E D$, conditional on $f_{\mathrm{m}^{\prime}}$ is given by

$$
\langle E D\rangle=1-R_{f_{\mathrm{m}}}(t)
$$

which, in view of the nonlinear relationship between uncertainty and heterogeneity in $R_{f_{\mathrm{m}}}(t)$, was approximated using a second-order estimate of $\left\langle R_{f_{\mathrm{m}}}(t)\right\rangle$ (see Bogen and Spear, 1987):

$$
\begin{aligned}
\langle E D\rangle & =1-R_{f_{\mathrm{m}}}(t)=\left\langle 1-[R(t)]^{f_{\mathrm{m}}}\right\rangle \\
& \approx 1-\left\{[R(t)]^{\left(f_{\mathrm{m}}\right\rangle}+\left(\frac{1}{2} \times \frac{\partial^{2} R_{f_{\mathrm{m}}}(t)}{\partial f_{\mathrm{m}}^{2}} \times \sigma_{f_{\mathrm{m}}}^{2}\right)\right\} \\
& \approx 1-\left\{[R(t)]^{\left(f_{\mathrm{m}}\right\rangle} \times\left(1+\frac{\{\ln [R(t)]]^{2} \times \sigma_{f_{\mathrm{m}}}^{2}}{2}\right)\right\},
\end{aligned}
$$

the final step of which follows from the fact that $\frac{\partial^{2} x^{a}}{\partial a^{2}}=x^{a}[\ln (x)]^{2}$ for any $x$ independent of $a$.

Further details concerning procedures useful for obtaining $\hat{E D}$, and $\overline{E D}$ and $\langle E D\rangle$ distributions are presented in Appendix B. 


\section{Cancer-Risk Model}

Because hypothetical residential low-dose exposure to TCE, such as might occur as a result of groundwater contamination at Site LF-13 of Beale Air Force Base, is assumed to have a positive, nearly constant slope at doses small enough to ensure lifetime excess cancer risk, $R$, is substantially less than one (i.e., $R<<1$ ), $R$ can be estimated by Eq. 13 :

$$
R \cong\left(E_{\text {Ing }} \times C S F_{\text {Ing }}\right)+\left(E_{\text {Derm }} \times C S F_{\text {Ing }}\right)+\left(E_{\text {Inh }} \times C S F_{\text {Inh }}\right),
$$

where $C S F_{\text {Ing }}$ is the oral cancer slope factor (CSF) for TCE [assumed to apply to both ingestion and dermal exposures (CalEPA/DTSC, 1994; USEPA Region 9, 1998)], and $C S F_{\text {Inh }}$ is the inhalation CSF for TCE that are reported by CalEPA (1996). Each CSF represents an upper-bound estimate of the probability of cancer per unit intake of TCE and unit body weight over a lifetime $\left[\right.$ i.e., $\left.\frac{\text { Risk }}{\mathrm{mg} /(\mathrm{kg}-\mathrm{d})}\right]$. The $C S F_{\text {Ing }}$ and $C S F_{\text {Inh }}$ parameters are treated as constants (Table 1).

The more traditional approach for arriving at estimators of risk can involve substituting into Eq. 13 those values for $E_{\mathrm{Ing},} E_{\mathrm{Inh}}$ and $E_{\mathrm{Derm}}$ that were all obtained using input parameters either at (1) means only, (2) regulatory defaults, in combination with mean values for parameters that are uncertain and upper bounds (e.g., $95^{\text {th }}$ percentiles, or where applicable $5^{\text {th }}$ percentiles, see footnote $c$ in Table 1) for parameters that are heterogeneous, where default values for such variates are not available or (3) upper bounds exclusively (e.g., $95^{\text {th }}$ percentiles, or where applicable $5^{\text {th }}$ percentiles, see footnote $\mathrm{c}$ in Table 1). In the first case, the value of $R$ equates to a "best" estimate, $\hat{R}_{\mathrm{E}}$. In the second case, the value of $R$ is considered to be for a "reasonably maximum exposed" person, $\hat{R}_{\mathrm{RME}}$. In the third case, the value of $R$ corresponds to an upper 
"conservative" bound, $\hat{R}_{\text {High }}$. All three of these types of risk-related estimators were calculated so these traditional-type estimators could be compared to analogous risk estimators that are more explicitly defined regarding uncertainty and/or variability. The input means used for calculating $\hat{R}_{\mathrm{E}}$ and the input upper bounds [e.g., $95^{\text {th }}$ percentiles; or where applicable, the $5^{\text {th }}$-percentile values (see footnote $c$ in Table 1)] used for calculating $\hat{R}_{\text {High }}$ all appear in Table 1. The default inputs used for calculating $\hat{R}_{\mathrm{RME}}$ appear in Table 2, with the expected values and $95^{\mathrm{th}}$-percentile upper-bound values [or where applicable, $5^{\text {th }}$-percentile values (see footnote $c$ in Table 1)] appearing in Table 1 for those uncertain and heterogeneous variates, respectively, for which default values are not given. Thus, the $\hat{R}_{\mathrm{RME}}$ is considered to be a conservative estimate of risk (i.e., above the average) that is within the range of reasonable possibilities, and is not the worst-possible case (USEPA, 1989 and 1991).

Risk-related estimators explicitly defined regarding uncertainty and/or variability involve the conditional expectations $\bar{R}$ and $\langle R\rangle$ (Bogen and Spear, 1987; NRC, 1994; Bogen, 1995). $\bar{R}$-type estimators of risk involve $\bar{R}$, which represents uncertain lifetime cancer risk to a (hypothetical) person at a population-average level of risk relative to others. The symbols $\bar{R}_{.05}$ and $\bar{R}_{.95}$ are used to represent the two-tailed lower and upper $90 \%$ confidence limits on the cumulative distribution function (cdf) of $\bar{R}$; and $\langle\bar{R}\rangle$ denotes the expected value (i.e., expectation with respect to uncertainty) of $\bar{R}$. $\langle R\rangle$-type estimators of risk involve $\langle R\rangle$, which denotes the set of expected values (with respect to uncertainty) of all the (potentially) different ("heterogeneous") cancer risks incurred within the population at risk. Thus, $\langle R\rangle_{.05}$ and $\langle R\rangle_{.95}$ represent the twotailed lower and upper $90 \%$ confidence limits on the $\operatorname{cdf}\langle R\rangle$; and $\overline{\langle R\rangle}$ is the 
population-average value of $\langle R\rangle$. (Note that the "population average" or arithmetic-mean value of a heterogeneous variate is just the expected value of that variate within a defined population. Expectations of lifetime-excess cancer risk, $R$, with respect to variability (i.e., $\bar{R}$ ) and uncertainty (i.e., $\langle R\rangle$ ) are defined by

$$
\begin{aligned}
& \bar{R}=\left(\bar{E}_{\text {Ing }} \times C S F_{\text {Ing }}\right)+\left(\bar{E}_{\text {Inh }} \times C S F_{\text {Inh }}\right)+\left(\bar{E}_{\text {Derm }} \times C S F_{\text {Ing }}\right), \text { and } \\
& \langle R\rangle=\left(\left\langle E_{\text {Ing }}\right\rangle \times C S F_{\text {Ing }}\right)+\left(\left\langle E_{\text {Inh }}\right\rangle \times C S F_{\text {Inh }}\right)+\left(\left\langle E_{\text {Derm }}\right\rangle \times C S F_{\text {Ing }}\right),
\end{aligned}
$$

where the terms $E_{\mathrm{Ing}} E_{\mathrm{Iul}}$, and $E_{\mathrm{Derm}}$ are defined in Equations 1-3, and $C S F_{\text {Ing }}$ and $C S F_{\text {Inh }}$ are described in the text following Eq. 13 (i.e., treated as constants and reported by CalEPA/DTSC, 1994; and/or USEPA Region 9, 1998).

The term $R^{*}$ denotes an upper-bound estimate with respect to JUV in risk. Specifically, $R_{95}^{*}$ denotes the risk to an individual who is at a $95^{\text {th }}$-percentile level of risk relative to those risks incurred by others in the population at risk. Alternative first-order approximations of this upper-bound JUV estimator (see Bogen, 1995) are given by

$$
R_{95}^{*}=\bar{R}_{95} \times \rho_{.95} \quad \text { or } \quad R_{.95}^{*}=\langle R\rangle_{.95} \times \rho_{.95}^{\prime}
$$

where the terms $\rho_{.95}$ and $\rho_{.95}^{\prime}$ denote "dispersion" ratios between upper-bound risk and expected individual risk; that is,

$$
\rho_{.95}=\frac{\langle R\rangle}{\langle\bar{R}\rangle} \quad \text { and } \quad \rho_{.95}^{\prime}=\frac{\bar{R}_{.95}}{\langle\bar{R}\rangle}
$$


Note that $\rho_{95}$ may be interpreted as an index of the "inequity" reflected in the distribution of individual risks incurred by a population at risk, insofar as this ratio is proportional to the variance (which measures interindividual differences) in that population. Similarly, $\rho_{.95}^{\prime}$ represents an index of uncertainty associated with individual risk.

For a population of size $n_{\mathrm{T}}, N$ is used to denote the uncertain number of additional cancer cases due to $R$, where expected number of cases is defined as $\langle N\rangle=n_{\mathrm{T}} \times\langle\bar{R}\rangle$. Of specific interest to stakeholders and decision makers may be the probability, $1-P_{0}$, that for a given population $n_{\mathrm{T}}$, there will be one or more additional cases of cancer (i.e., the probability that $N \geq 1$ ).

The value of $P_{0}$ can be well approximated generally (see Bogen and Spear, 1987; NRC, 1994; Bogen, 1995) by the integral of the conditional Poisson likelihood function:

$$
P_{o} \approx \int_{0}^{1} e^{-n_{\mathrm{T}} \bar{R}} f_{\bar{R}}(\bar{R}) \mathrm{d} \bar{R}
$$

where the compound-Poisson variate, $n_{\mathrm{T}} \bar{R}$, incorporates the uncertain parameter $\bar{R}$ defined in Eq. 14. (Further details concerning the procedure for obtaining $P_{0}$ can be found in the last section of Appendix B.)

\section{Calculations}

Variabilities in route-specific intake-related quantities $(\operatorname{Ing}, \operatorname{Inh}, A$-defined after Eqs. 1, 2, and 3, respectively) were calculated using corresponding demographic and exposure-related data cited in Table 1 . Note that variability in each quantity necessarily depends on the duration of exposure $(E D)$ experienced by the population at risk. If all 
people were exposed for an entire lifetime, then this variability is properly characterized as the distribution of the lifetime, time-weighted-average (TWA) value of the corresponding quantity $(\operatorname{Ing}, \operatorname{Inh}$, or $A)$. In contrast, if exposure duration were in all cases very brief, then this variability for each quantity would better be characterized as the composite distribution reflecting the weighted (or "age-adjusted") average of the age-specific distributions of that quantity, using age-specific population fractions as weights.

For the present analysis, all calculations of $\hat{R}_{\text {High }}$ used upper-bound $\left(95^{\text {th }}\right.$ percentile) values (listed in Table 1) of the lifetime TWA distributions of variability in Inh, Ing, and $A\left(\hat{R}_{\mathrm{E}}\right.$ and $\hat{R}_{\mathrm{RME}}$ used means listed in Table 1 and default values listed in Table 2, respectively, for these same three inputs). All other output riskcharacterization quantities were calculated using corresponding composite, "ageadjusted" distributions reflecting people of all ages within the modeled exposed population. The latter procedure used is necessarily "conservative", in the sense that for each quantity the composite distribution (which is a weighted mixture of agespecific distributions) is necessarily more broad (i.e., has a larger variance) than the corresponding lifetime TWA distribution (which is the distribution of a weighted sum of random variate values). Thus, the larger $E D$, the more likely exposure will involve more than one of the age ranges used to construct the composite distribution, and hence the relevant quantity would more accurately be calculated as a TWA value involving the age ranges involved.

Ideally, computation would involve sampling a value of $E D$ as well as a starting age, and then calculating (or, via a lookup method employing pre-calculated distributions, selecting) the relevant variability distributions for Ing, Inh, and A. This procedure is numerically taxing, however, so the alternative, simpler, albeit somewhat 
conservative, approach described above was used instead. This approach implies only very little conservatism in the case of risk characterizations involving $\langle R\rangle$, because the $\langle E D\rangle$ distribution was highly skewed (with a median value of only approximately $2 \mathrm{y}$ ), due to the highly skewed nature of residential turnover $R(t)$. Somewhat greater conservatism is implied for risk characterizations involving $\bar{R}$, because $\overline{E D}$, not nearly as skewed, has a median value of approximately $7 \mathrm{y}$.

For the reasons discussed above, the calculation of $E_{\text {Ing }}$ was based on the Ershow and Cantor (1989) lognormal approximation of the composite distribution reflecting variability in tap-water ingestion per $\mathrm{kg}$ body weight by people of all ages in the Western Region of the US. The corresponding lifetime TWA distribution was calculated assuming a 70-y lifespan and using the age-specific intakes reported by Ershow and Cantor (1989). The mean for both distributions was nearly the same.

The calculation of $E_{\text {Inh }}$ was based on age-specific rates of total inhalation per $\mathrm{kg}$ body weight for California youth and adults (data collected by Adams, 1993, and Wiley et al., 1991a,b; were reevaluated and presented by OEHHA, 1996; according to discussion with Marty, 1998). From these data a corresponding composite distribution was calculated using youth and adult population weights derived from national census data (USCB, 1998), and a corresponding lifctime TWA distribution was calculated using $\frac{12}{70}$ and $\frac{58}{70}$ as exposure-duration weights for youth and adults, respectively. The mean for both distributions was the same.

The calculation of $E_{\text {Derm }}$ was based on age-specific estimates of body surface area per kg body weight, A, reported by Phillips et al. (1993). From these data a corresponding composite distribution was calculated using infant/toddler, youth, and adult population weights derived from national census data (USCB, 1998), and a 
corresponding lifetime TWA distribution was calculated using $\frac{2}{70}, \frac{16}{70}$, and $\frac{52}{70}$ as exposure-duration weights for the respective age groups. The mean for both distributions was the same.

Calculations of derived input-variate distributions, the output $\bar{R}$ and $\langle R\rangle$ distributions, and related estimators were performed by Monte-Carol simulations using Crystal Ball ${ }^{\circledast}$, version 4.0 (Decisioneering, Inc., 1996), and/or Mathematica ${ }^{\oplus}$, version 3.0 (Wolfram, 1996). Appendix B contains further explanations of (1) additional procedures useful for generating several different input-variate distributions and corresponding expected values and upper bounds; (2) the approach for deterministically calculating exposure and traditional risk-related (point) estimators; and (3) methods for estimating the probability of zero additional cases of cancer $\left(P_{0}\right)$.

\section{RESULTS}

Table 3 summarizes the lifetime excess cancer risk-related estimates for hypothetical residents theoretically supplied ground water from beneath Site LF-13 at Beale Air Force Base that contains the 1997 measured, low-level concentrations of TCE (Purrier, 1997). The traditional risk-related estimator approach yields values of $\hat{R}_{\mathrm{E}}$, $\hat{R}_{\mathrm{RME}}$, and $\hat{R}_{\mathrm{High}}$ equal to $3.1 \times 10^{-6}, 6.1 \times 10^{-5}$, and $2.4 \times 10^{-4}$, respectively [further details concerning the calculations of these traditional risk-related (point) estimators and also those for exposure (i.e., daily dose or intake) can be found in Table B-4 and related text of Appendix B]. The risk-related estimator approach that is explicit regarding 
Table 3. Lifetime excess cancer risk-related estimates for hypothetical residents adjacent to Beale Air Force Base in California, based on multiple-pathway (i.e., ingestion, inhalation, and dermal) exposures to ground water containing low-levels of trichloroethylene (TCE).

\begin{tabular}{|c|c|c|c|}
\hline $\begin{array}{l}\text { Risk-related estimator approach } \\
\text { Type of estimator }\end{array}$ & Symbol $^{\mathrm{a}}$ & Value & $\begin{array}{l}\text { CVM } \\
(\%)^{b}\end{array}$ \\
\hline \multicolumn{4}{|l|}{ Traditional } \\
\hline "Best" estimate (using input means) & $\hat{R}_{\mathrm{E}}$ & $3.1 \times 10^{6}$ & NA \\
\hline Risk to "reasonably maximum exposed" person & $\hat{R}_{\mathrm{RME}}$ & $6.1 \times 10^{-5}$ & NA \\
\hline Upper "conservative" bound & $\hat{R}_{\mathrm{High}}$ & $2.4 \times 10^{-4}$ & NA \\
\hline
\end{tabular}

Explicit regarding uncertainty and/or variability in:

$>$ population-average risk, $\bar{R}$

Expectation (with respect to uncertainty)

$\langle\bar{R}\rangle \quad 3.1 \times 10^{-6} \quad \mathrm{NA}$

Lower uncertainty bound

$\bar{R}_{.05} \quad 1.4 \times 10^{-6} \quad 0.46$

Upper uncertainty bound

$\bar{R}_{.95} \quad 5.5 \times 10^{-6} \quad 0.45$

$>$ expected risk (with respect to uncertainty), $\langle R\rangle$

Population average

Lower variability bound

Upper variability bound

$\overline{\langle R\rangle} \quad 3.1 \times 10^{-6} \quad \mathrm{NA}$

$\langle R\rangle_{.05} \quad 3.6 \times 10^{-8} \quad 0.97$

$\langle R\rangle_{.95} \quad 1.4 \times 10^{-5} \quad 1.2$

$>$ jointly uncertain and heterogeneous risk

$\begin{array}{lccc}\text { Index of "inequity" in expected risk } & \rho_{.95} & 4.7 & 0.58 \\ \text { Upper JUV bound } & R_{.95}^{*} & 2.6 \times 10^{-5} & 0.62\end{array}$

a Note that $\hat{R}_{\mathrm{E}},\langle\bar{R}\rangle$, and $\overline{\langle R\rangle}$ denote threc closely related estimators of mean risk; that $\hat{R}_{\mathrm{RME}}$ and $\hat{R}_{\mathrm{High}}$ are crude and typically conservative approximations of $R_{95}^{*}$; and that JUV refers to joint uncertainty and variability.

' Coefficient of variation of the mean (expressed in percent), CVM $\%=100 \% \times \frac{\tilde{\sigma}}{\tilde{X} \times \sqrt{m}}$, where $\tilde{\sigma}$ is the sample standard deviation and $\tilde{X}$ is, for each estimator, the sample arithmetic mean obtained from $m$ equal to 10 repeated Monte-Carlo simulations each involving 2,000 trials. Small CVM\% values (i.e., $<2 \%$ ) indicate the estimates obtained are highly reliable, despite Monte-Carlo sampling error. A CVM\% value is not applicable (NA), when value of risk-related estimator was not estimated by simulation, but rather was calculated using the corresponding exact expression. 
uncertainty in population-average risk, $\bar{R}$, produces a value for $\langle\bar{R}\rangle$ equal to $3.1 \times 10^{-6}$, and two-tailed lower and upper $90 \%$ confidence limits on the cdf of $\bar{R}$ equal to $1.4 \times 10^{-6}$ for $\bar{R}_{.05}$, and $5.5 \times 10^{-6}$ for $\bar{R}_{.95}$. The risk-related estimator approach that is explicit regarding variability in expected risk (with respect to uncertainty), $\langle R\rangle$, produces a value for $\overline{\langle R\rangle}$ equal to $3.1 \times 10^{-6}$, and two-tailed lower and upper $90 \%$ confidence limits on the cdf of $\langle R\rangle$ equal to $3.6 \times 10^{-8}$ for $\langle R\rangle_{.05}$ and $1.4 \times 10^{-5}$ for $\langle R\rangle_{.95}$. The index of "inequity" in expected risk (or "dispersion" ratio), $\rho_{95}$, equals 4.7 , which is not substantial (i.e., less than a factor of 10) and therefore indicates there is not a great amount of interindividual variability within the population in this situation. The upper JUV bound $\left(R_{.95}^{*}\right)$, which is approximated by the product of $\bar{R}_{.95}$ and $\rho_{95}$ equals $2.6 \times 10^{-5}$. (The result was nearly identical using $\rho_{.95}^{\prime}$ to estimate $R_{.95}^{*}$-see Eq. 16). Both the upper-bound population-average risk estimator, $\bar{R}_{.95}$, and the upper-JUV-bound risk esimator, $R_{.95}^{*}$, have values less than $10^{-4}$ and within the range of acceptability (i.e., $10^{-4}$ to $\leq 10^{-6}$ ) with respect to generally followed regulatory guidance (USEPA, 1990).

Table 4 contains the results of the analysis of population risk associated with multipathway exposures to the TCE-contaminated ground water. These results reveal that the probability $\left(1-P_{0}\right)$ of greater than zero additional cases of cancer for local on-ground, exposed populations of up to several hundred (i.e., corresponding to $n$ individuals; which is the reasonably foreseeable short-term scenario), is less than 0.01 . Even for $n$ up to 26,900 , the probability of more than zero cases remains below 0.5 . 
Table 4. Population risk associated with multipathway exposures to TCE-contaminated ground water at Beale Air Force Base in California.

\begin{tabular}{ccccc}
\hline $\begin{array}{c}\text { Total } \\
\text { exposed } \\
\text { population } \\
\text { over 70 y, } \\
n_{\mathrm{T}}\end{array}$ & $\begin{array}{c}\text { Exposed } \\
\text { population } \\
\text { during 7.6 y, } \\
n^{\mathrm{a}}\end{array}$ & $\begin{array}{c}\text { Probability of } \\
>0 \text { additional } \\
\text { cases of cancer, } \\
1-P_{0}^{\mathrm{b}}\end{array}$ & $\mathrm{CVM}^{\mathrm{c}}$ & $\begin{array}{c}\text { Expected value of the } \\
\text { total number of } \\
\text { additional cancer cases, } \\
\langle N\rangle=n_{\mathrm{T}} \times\langle\bar{R}\rangle\end{array}$ \\
\hline 100 & 11 & 0.0003 & $0.00030 \%$ & 0.00031 \\
2,000 & 217 & 0.0063 & $0.0053 \%$ & 0.0062 \\
30,000 & 3,257 & 0.0879 & $0.022 \%$ & 0.094 \\
$247,766.9$ & 26,900 & 0.5000 & $0.031 \%$ & 0.77 \\
\hline
\end{tabular}

${ }^{\text {a }}$ Here $n$ denotes the number of individuals residing at the impacted site within any 7.6-y time interval (i.e., the expected value, $\langle\overline{E D}\rangle$, of uncertain exposure duration, $\overline{E D}$, for the average exposed person) during the total 70-y time period considered (i.e., $n=$ $n_{\mathrm{T}} \times \frac{7.6 \mathrm{y}}{70 \mathrm{y}}$ ). Note that $n$ is not used to compute $P_{0}$, and is shown rounded to the nearest integer.

${ }^{\mathrm{b}}$ Each value listed is the mean of 10 estimates obtained using the $\bar{R}$ distributions generated by 10 corresponding Monte-Carlo simulations, each involving 2,000 trials (see Appendix B for further explanation).

${ }^{c}$ Coefficient of variation of the mean (CVM, and expressed in percent) was derived as explained in Table 3 , footnote $b$.

In fact, the expected value of the total number of additional cancer cases remains less than 0.01 for $n$ up to several hundred and does not exceed 0.5 until $n$ exceeds 26,900 . Even then, it is not clear that the extraction well would be capable of supporting such a large on-ground population, or even the comparable total exposed population over $70 \mathrm{y}\left(\right.$ i.e., $n_{\mathrm{T}}$ ) that is equal to 247,767 .

The Monte-Carlo sampling errors indicated in Tables 3 and 4 are all small [i.e., coefficient of variation of the mean $(\mathrm{CVM})$, expressed in percent $(\%)<2 \%$; see 
footnote $\mathrm{b}$ in Table 3 for equation]. This result addresses the issue of Monte-Carlo quality-control and assures that corresponding estimates are highly reliable.

\section{DISCUSSION AND CONCLUSIONS}

Bogen (1995) has shown that upper-bound estimators of JUV in risk may be approximated using calculations involving cumulative distribution functions (cdfs) that reflect only uncertainty and only interindividual variability, thus avoiding relatively tedious "nested" Monte-Carlo techniques that are otherwise required to obtain estimators of JUV in risk. The approximation procedure was successfully employed for this analysis of uncertainty and variability in exposure to characterize risk from TCEcontaminated ground water at Site LF-13 on Beale Air Force Base in California. Comparing the results of this approach to the more traditional one shows that the riskestimators computed more traditionally overestimate the risk to an upper-bound individual $R_{.95}^{*}$, when JUV in the population is addressed explicitly. Furthermore, it can be seen from the results in Table 3 that $\hat{R}_{E},\langle\bar{R}\rangle$, and $\overline{\langle R\rangle}$ all represent expected risk to the average individual. The equality between $\langle\bar{R}\rangle$ and $\overline{\langle R\rangle}$ (and hence the consistency between the alternative $R_{.95}^{*}$ estimates) suggests that the first-order approximation approach for $R_{.95}^{*}$ is reliable in this case. More accurate $R_{.95}^{*}$ estimation would require numerically intensive nested Monte-Carlo methods.

Results presented in Table 4 indicate that the greater the exposed population, the less likely will be the chance that there will be zero observed cases. However in this analysis, for $n$ in the hundreds, there is a probability of less than 0.01 that the number of additional cases will be greater than zero. Even for $n$ up to 26,900 , the probability of 
more than zero cases remains less than 0.5. Clearly, this information is more valuable than that provided by a single, point estimate of $\langle N\rangle$ alone, especially for large populations (e.g., $n_{\mathrm{T}}$ is 247,767$)$ where $\langle N\rangle$ approaches but does not exceed 1, and there is really no measure of confidence (or uncertainty) associated with just that expected value.

On the basis of this risk analysis of the TCE-contaminated ground water beneath Site LF-13 at Beale Air Force Base, and as pointed out by Bogen (1995), specific risk estimators might provide the bases for risk-acceptability criteria for a site, along with a specified value for $1-P_{0}$. For example, risk-acceptability criteria might take the form of a joint requirement that $\bar{R}_{95}$ be at least within range of generally followed regulatory guidance $10^{-6}$ to $10^{-4}$ (USEPA, 1990); and $\rho_{95}<10^{2} ; R_{.95}^{*} £ 10^{-4}$; and $1-P_{0}<0.5$. Under such conditions, the upper-bound population-average risk, $\bar{R}_{95}$, is low and within generally accepted regulatory limits; there does not appear to be a great amount of interindividual variability within the population, because the index of "inequity" in expected risk, $\rho_{.95}$ is not substantial and so special susceptible groups do not need consideration; relatively highly exposed people in the population are not incurring inordinate risk as $R_{95}^{*}$ is even less than $10^{-4}$; and the probability of 1 or more cases of cancer is less than 0.5 for a reasonably foreseeable population equal to $n$ and an expected exposure duration of $7.6 \mathrm{y}$. Clearly, the results presented here for the TCEcontamination of ground water addressed at Site LF-13 at Beale Air Force Base meet these requirements and such risk criteria for this site can ensure that individual lifetime risks are both de minimis and equitable.

The more traditional estimates of risk in this case all overestimate the level of risk to the upper-bound individual, including $\hat{R}_{\mathrm{RME}}$. Therefore, while providing an 
expedient and standardized assessment tool for screening risk levels at a particular site, such traditional approaches to estimating risk will always overestimate upper-bound individual risk, and may lead regulatory agencies to impose more stringent and costly remediation standards than might otherwise be appropriate. The approach illustrated in this report for TCE-contaminated ground water at Site LF-13 on Beale Air Force Base demonstrates a systematic mechanism for deriving risk-acceptability criteria that can help convince decision makers and stakeholders that money and resources being dedicated to remediation might better spent on other public health measures that might be more cost effective.

The results of this work reinforce the importance of considering variability and uncertainty in estimates of risk. They also illustrate that the calculations can be readily performed by applying commercially available software for desktop computers, and will yield information of sufficient detail to establish rcasonable and equitable sitespccific risk-acceptability criteria. 


\section{REFERENCES}

Adams, W. (1993), Measurement of Breathing Rate and Volume in Routinely Performed Daily Activities, prepared for California Air Resources Board, Research Division, Sacramento, CA.

American Relocation Center (ARC) (1999), All About Buyer Representation, American Relocation Center, Administrative Offices, Shawnee Mission; KS, available online at http://www.buyingrealestate.com/pages/article/article2.html, May 3, 1999.

Bogen, K.T. (1995), Methods to Approximate Joint Uncertainty and Variability in Risk, Risk Analysis 15(3): 411-419.

Bogen, K.T., and R.C. Spear (1987), Integrating Uncertainty and Interindividual Variability in Environmental Risk Assessment, Risk Analysis 7(4): 427-436.

Bogen, K.T., G.A. Keating, S. Meissner, and J.S. Vogel (1998), Initial Uptake Kinetics in Human Skin Exposed to Dilute Aqueous Trichloroethylene in Vitro, J. Exposure Analysis Environ. Epidemiol. 8(2): 253-271.

Brown, A.H., D.R. Bishop, and C.R. Rowan (1984), The Role of Skin Absorption as a Route of Exposure for Volatile Organic Compounds (VOCs) in Drinking Water, Am. J. Publ. Health 74: 479-484.

Burmaster, D.E. (1998), A Lognormal Distribution for Time Spent Showering, Risk Analysis 18(1): 33-35.

California Environmental Protection Agency (CalEPA) (1996), California Cancer Potency Factors: Update. Memorandum to Cal/EPA Departments, Boards, and Offices from Standards and Criteria Work Group, Sacramento, CA, April 1, 1996 (originally prepared in November 1994).

California Environmental Protection Agency, Department of Toxic Substances Control (CalEPA/DTSC) (1994), Preliminary Endangerment Assessment (PEA) Guidance Manual (A guidance manual for evaluating hazardous substances release sites), California Environmental Protection Agency, Department of Toxic Substances Control, Sacramento, CA (January 1994).

Corsi, R.L., and C. Howard (1998), Shower Database, in Volatilization Rates From Water to Indoor Air: Phase II, prepared for United States Environmental Protection Agency, Office of Research and Development, The National Center for Environmental Assessment, Washington, DC (Technical Merit Review Draft, released for citation by J. Moya, EPA Project Officer) Grant Number CR 824228-01, pp. 167-193.

Decisioneering, Inc. (1996), Crystal Ball ${ }^{\oplus}$, Forecasting and Risk Analysis for Spreadsheet Users, Version 4.0, Decisioneering, Inc., Denver, $\mathrm{CO}$. 
Duke-Williams, O. (1999), Special Migration Statistics, Center for Computational Geography, School of Geography, University of Leeds, Leeds, UK, available online at http://www.geog.leeds.ac.uk/staff/o.äuke-williams/sms.html, May 3, 1999 [see also conference publication by P. Rees and O. Duke-Williams (1995), The Special Migration Statistics: A Vital Resource for Research Into British Migration, Annual Conference of the Institute of British Geographers, University of Northumbria at Newcastle, January 1995; cited online at http://www.geog.leeds.ac.uk/staff/o.duke-williams/pubs.html, May 3, 1999].

Ershow, A.G., and K.P. Cantor (1989),Total Water and Tapwater Intake in the United States: Population-Based Estimates of Quantities and Sources, prepared under National Cancer Institute Order \#263-MD-810264 by the Life Sciences Research Office, Federation of American Societies for Experimental Biology, Bethesda MD.

Fisk, W.J, R.K. Spencer, D.T. Grimsrud, F.J. Offermann, B. Pedersen, and R. Sextro (1987), Indoor Air Quality Control Techniques, Radon, Formaldehyde, Combustion Products, Pollution Technology Review No. 44, Noyes Data Corp., Park Ridge, NJ.

Giardino, N.J., N.A. Esmen, and J.B. Andelman (1992), Modeling Volatilization of Trichloroethylene from a Domestic Shower Spray: The Role of Drop-Size Distribution, Environ. Sci. Technol. 26, 1602-1606.

James, I.R., and M.W. Knuiman (1987), An Application of Bayes Methodology to the Analysis of Diary Records from a Water Use Study, J. Am. Stat. Assoc. 82(399): 705-711.

Israeli, M., and C.B. Nelson (1992), Distribution and Expected Time of Residence for U.S. Households, Risk Analysis 12(1): 65-72.

Marty, M. (1998), Personal Communication Regarding the Methodology Used by OEHHA Staff to Develop Breathing Rate per Unit Body. Weight Distribution From Data of Adams (1993) and Wiley et al. (1991a,b) and Presented in OEHHA (1996), Office of Environmental Health Hazard Assessment (OEHHA), - California Environmental Protection Agency, Berkeley CA.

McKone, T.E. (1987), Human Exposure to Volatile Organic Compounds in Household Tap Water: The Indoor Inhalation Pathway, Environ. Sci. Technol. 21: 1194-1201.

McKone, T.E., and K.T. Bogen (1992), Uncertainties in Health-Risk Assessment: An Integrated Case Study Based on Tetrachloroethylene in California Groundwater, Regul. Toxicol. Pharmacol. 15: 86-103.

National Research Council (NRC), Committee on Risk Assessment of Hazardous Air Pollutants (1994), Science and Judgment in Risk Assessment, National Academy Press, Washington, DC.

Office of Environmental Health Hazard Assessment (OEHHA), California Environmental Protection Agency (1996), Exposure Assessment and Stochastic Analysis, Air Toxics Hot Spots Program, Risk Assessment Guidelines Part IV, Technical Support Document, Public Review Draft, Office of Environmental Health Hazard Assessment, California Environmental Protection Agency, Berkeley, CA. 
Phillips, L.J., R.J. Fares, and L.G. Schweer (1993), Distributions of Total Skin Surface Area to Body Weight Ratios for Use in Dermal Exposure Assessments, J. Exposure Analysis Environ. Epidem. 3(5): 331-338.

Purrier, W. (1997), Personal Communication Regarding Detailed Data for TCE Groundwater Concentration at USAF Site in Northern California, Law Engineering and Environmental Services, Inc., Sacramento, CA (December 1997).

Tsang, A., and N. Klepeis (1996), Results Tables from a Detailed Analysis of the National Human Activity Pattern Survey (NHAPS) Response. Draft Report prepared for the U.S. Environmental Protection Agency, Washington, DC, by Lockheed Martin, Contract No. 68-W6-001, Delivery Order No. 13.

URS Greiner Woodward Clyde (URSGWC) in Omaha, Nebraska (1998), Management Action Plan, Beale Air Force Base, California, December 1998, prepared for Headquarters Air Combat Command (ACC), Langley Air Force Base, VA, under contract to US Air Force Center for Environmental Excellence (AFCEE), Brooks Air Force Base, TX, Project No. ACCH19987544, obtain from Chief, Environmental Restoration (M.E. O'Brien), Beale Air Force Base, California.

United States Census Bureau (USCB) (1997), Geographic Mobility of People 1 Year Old and Older, By Sex, Between March 1996 and March 1997, source: March 1997 Current Population Survey (CPS), last revised September 29, 1997, US Bureau of the Census, Washington, DC, available online at http://www.bls.census.gov/cps/pub/7997/mobility.htm, May 3, 1999.

United States Census Bureau (USCB) (1998), Resident Population of the United States: Estimates by Age and Sex, source: United States Population Estimates, by Age, Sex, Race, and Hispanic Origin, 1990 to 1997 (with associated updated tables for recent months), last revised December 28, 1998, Population Division, US Bureau of the Census, Washington, DC, available online "at http://www.census.gov/population/ estimates/nation/intfile2-1.txt, May 3, 1999.

United States Environmental Protection Agency (USEPA) (1989), Risk Assessment Guidance for Superfund Volume 1: Human Health Evaluation Manual, Interim Final, Office of Emergency and Remedial Response, U.S. Environmental Protection Agency, Washington, DC, EPA/540/1-89/002.

United States Environmental Protection Agency (USEPA) (1990), National Oil and Hazardous Substances Pollution Contingency Plan Final Rule (40 CFR Part 300), Fed. Regist. 55(46): 8666-8865; particularly 8715-8719 (March 8, 1990).

United States Environmental Protection Agency (USEPA) (1991), Risk Assessment Guidance for Superfund Volume 1: Human Health Evaluation Manual, Supplemental Guidance: Standard Default Exposure Factors, Interim Final, Office of Emergency and Remedial Response, Toxics Integration Branch, U.S. Environmental Protection Agency, Washington, DC, OSWER Directive: 9285.6-03. 
United States Environmental Protection Agency (USEPA) (1997), Exposure Factors Handbook, Volumes I-III, Final, Office of Research and Development, National Center for Environmental Assessment, U.S. Environmental Protection Agency, Washington, D.C., EPA/600/P-95/002F (August 1997).

United States Environmental Protection Agency Region 9 (USEPA Region 9) (1998), Region 9 Preliminary Remediation Goals (PRGs) 1998, Technical Support Team, U.S. Environmental Protection Agency Region IX, San Francisco, CA, available online at http://www.epa.gov/region09/waste/sfund/prg/ .

Wiley, J.A., J.P. Robinson, T. Piazza, K. Garrett, K. Cirksena, Y.T. Cheng, and G. Martin (1991a), Activity Patterns of California Residents, prepared for California Air Resources Board, Research Division, ARB/R-93/487, Sacramento, CA (available from National Technical Information Service, Springfield, VA).

Wiley, J.A., J.P. Robinson, Y.T. Cheng, T. Piazza, L. Stork, and K. Pladsen (1991b), Study of Children's Activity Patterns, prepared for California Air Resources Board, Research Division, ARB/9-93/489, Sacramento, CA (available from National Technical Information Service, Springfield, VA).

Wolfram, S. (1996), The Mathematica Book, $3^{\text {rd }}$ ed., Wolfram Media/Cambridge University Press, Cambridge, UK. 


\section{APPENDIX A \\ Glossary of Important Terms}

\begin{tabular}{l}
\hline Terminology \\
\hline Constant \\
Deterministic, \\
screening-level calculation \\
of exposure and risk
\end{tabular}

Exposure pathways considered
Joint uncertainty and interindividual variability (JUV) in predicted risk

JUV notation: overbar and angle brackets

\section{Explanation}

An input parameter that is assumed to be correct-neither uncertain nor variable.

A model that commonly involves using upperbound point estimates for input parameters that are not considered to be constant in order to generate a conservative point estimate of risk.

Direct ingestion $\left(E_{\mathrm{Ing}}\right)$ of substancecontaminated groundwater; inhalation $\left(E_{\text {Inh }}\right)$ of substance volatilized from contaminated groundwater into residential indoor air; and dermal absorption $\left(E_{\text {Derm }}\right)$ of substance while using contaminated groundwater for showering or bathing [contaminant intake from each exposure pathway is expressed in units of $\mathrm{mg} /(\mathrm{kg}-\mathrm{d})$; see Eqs. 1, 2, and 3, respectively].

True differences (i.e., heterogeneity) in a riskrelated characteristic (e.g., physiological differences) associated with different individuals in a population at risk (see Table 1).

The uncertainty and interindividual variability in predicted risk, based on the uncertainty and/or interindividual variability in one or more input parameters.

An overbar (i.e., -) denotes mathematical expectation with respect to heterogeneous parameters only, and angle brackets (i.e., \langle\rangle ) denote mathematical expectation with respect to uncertain parameters only. Additionally, \langle\rangle represents expectation with respect to uncertainty, after expectation with respect to heterogeneity, and $\overline{\langle\rangle}$ represents a population-average value of expectations with respect to uncertainty. 


\section{Glossary of Important Terms (continued)}

\begin{tabular}{|c|c|}
\hline Terminology & $\begin{array}{r}\text { Explanation } \\
\end{array}$ \\
\hline Monte-Carlo simulation & $\begin{array}{l}\text { A mechanism for randomly selecting values } \\
\text { from an input distribution or distributions in } \\
\text { order to generate an output distribution for a } \\
\text { probabilistic model. }\end{array}$ \\
\hline $\begin{array}{l}\text { Probabilistic approach to } \\
\text { estimating exposure and } \\
\text { risk }\end{array}$ & $\begin{array}{l}\text { A model that permits the entire distribution of } \\
\text { an input parameter, which is not considered to } \\
\text { be constant, to be used and combined with } \\
\text { distributions of other input parameters, as well } \\
\text { as constants, in order to generate a } \\
\text { distribution for possible outcomes. }\end{array}$ \\
\hline Total Risk $(R)$ & $\begin{array}{l}\text { The increased lifetime probability of cancer for } \\
\text { an individual attributable to exposure to a } \\
\text { chemical by one or more physiological intake } \\
\text { pathways (e.g., ingestion, inhalation, and } \\
\text { dermal absorption) (see Eqs. } 13 \text { through } 15 \text { in } \\
\text { text). }\end{array}$ \\
\hline Uncertainty & $\begin{array}{l}\text { Lack of knowledge concerning the true value } \\
\text { of a risk-related variate (see Table } 1 \text { in text). }\end{array}$ \\
\hline
\end{tabular}


APPENDIX B

Further Explanations of

(1). Additional Procedures Useful for Generating Several Different Input-Variate Distributions, and Corresponding Expected Values and Upper-Bounds; (2) The Approach For Deterministically Calculating Exposure and Traditional Risk-Related (Point) Estimators, and (3) Methods for Estimating the Probability of Zero Additional Cases of Cancer $\left(P_{0}\right)$

In order to address uncertainty and variability in exposure (as noted in Eq. 14 and 15 in text), as well as obtain more traditional values equating to a "best" estimate, a "reasonable maximum exposure", and an upper "conservative" bound for exposure and risk, appropriate distributions for input variates must be constructed and used for nonconstant terms in Eqs. 1 through 3 in text (also see Table 1 in text). For example, details of distribution types and attributes for all inputs of water-use rates and waterexposure times (see Eq. 2 in text), as well as for the skin-permeability coefficient (see Eq. 3 in text), were obtained directly from the literature (see Table 1 in text). One purpose of this appendix is to provide further explanation of additional methods involving a combination of a spreadsheet and Crystal Ball ${ }^{\circledR}$, version 4.0 (Decisioneering, Inc., 1996) computer software that can be used to construct several of the other input-variate distributions used by Eqs. 1 through 3, respectively, in text. Another purpose is to present the details of the approach for calculating traditional exposure and traditional risk-related (point) estimators. Finally, this appendix describes the procedure that can be performed using a spreadsheet and Crystal Ball ${ }^{\boxplus}$, version 4.0 (Decisioneering, Inc., 1996) computer software to estimate the probability of zero additional cases of cancer $P_{0}$ [and its complement, the probability of one or morc (i.c., $>0$ ) additional cases of cancer, $1-P_{0}$ ) in a total population, $n_{\mathrm{T}}$, over a 70 -year period. The explanations provided assume that the reader is familiar with the purpose and use of commercially 
available spreadsheet computer software and also software for performing Monte-Carlo simulations [e.g., Crystal Ball ${ }^{\circledR}$, version 4.0 (Decisioneering, Inc., 1996)].

\section{Exposure-Pathway Specific Intakes}

As discussed in the "Calculations" section of the text, two types of cumulative distribution funclions (cdfs) for each of the three route-specific intake-related quantities (i.e., Ing, Inh, and $A$-defined after Eqs. 1, 2, and 3, respectively, in text) need to be derived. The first type of $\mathrm{cdf}$ is a composite distribution reflecting the weighted functional average of age-specific cdfs for that quantity, using age-specific population fractions as weights. The composite distribution applies to someone picked at random from the population having an exposure duration likely to be experienced by the population at risk. The second type of cdf is a lifetime, time-weighted-average (TWA) distribution that represents a stochastic weighted sum of independent variate values each sampled from a corresponding age-specific cdf, using the corresponding fraction of lifespan as the weight. The expected (mean) and upper-bound $\left(95^{\text {th }}\right.$-percentile) values obtained from the lifetime, TWA distribution are used when considering characterizing exposure and risk for a person exposed for their entire lifetime.

Ingestion rate of drinking water [Ing; $L /(k g-d)]$

Ershow and Cantor (1989) derive a composite distribution reflecting variability in the ratio (Ing) of tap-water ingestion rate to body weight [L/(kg-d)] for people of both sexes in age groups between $0 \mathrm{y}$ and over $65 \mathrm{y}$ during all seasons in the Western Region of the US (see bottom row of Table B-1 for moments of composite distribution). This composite distribution is 
Table B-1. Weighting factor and age-specific ratios (Ings) of tapwater intakes to body weights [L/(kg-d)] for both sexes and all seasons for Western Region of US [from Table 36 in Ershow and Cantor (1989)].

\begin{tabular}{|c|c|c|c|c|c|}
\hline $\begin{array}{l}\text { Age } \\
\text { (y) }\end{array}$ & $\begin{array}{l}\text { Exposure- } \\
\text { duration } \\
\text { weighting } \\
\text { factor }\end{array}$ & $\begin{array}{l}\text { Arithmetic } \\
\text { mean } \\
{[\mathrm{L} /(\mathrm{kg}-\mathrm{d})]}\end{array}$ & $\begin{array}{l}\text { Arithmetic } \\
\text { standard } \\
\text { deviation } \\
{[\mathrm{L} /(\mathrm{kg}-\mathrm{d})]}\end{array}$ & $\begin{array}{l}\text { Geometric } \\
\text { mean } \\
{[\mathrm{L} /(\mathrm{kg}-\mathrm{d})]}\end{array}$ & $\begin{array}{l}\text { Geometric } \\
\text { standard } \\
\text { deviation } \\
{[\mathrm{L} /(\mathrm{kg}-\mathrm{d})]}\end{array}$ \\
\hline $\begin{array}{l}0 \text { to } \\
1\end{array}$ & $\begin{array}{l}1 / 70= \\
0.01428\end{array}$ & 0.0532 & 0.0509 & 0.0384 & 2.24 \\
\hline $\begin{array}{l}1 \text { through } \\
10\end{array}$ & $\begin{array}{l}10 / 70= \\
0.14286\end{array}$ & 0.0387 & 0.0238 & 0.0330 & 1.76 \\
\hline $\begin{array}{l}11 \text { through } \\
19\end{array}$ & $\begin{array}{l}9 / 70= \\
0.12857\end{array}$ & 0.0184 & 0.0107 & 0.0159 & 1.72 \\
\hline $\begin{array}{l}20 \text { through } \\
64\end{array}$ & $\begin{array}{l}45 / 70= \\
0.64286\end{array}$ & 0.0214 & 0.0122 & 0.0186 & 1.70 \\
\hline $\begin{array}{l}65 \text { to } \\
70\end{array}$ & $\begin{array}{l}5 / 70= \\
0.07143\end{array}$ & 0.0231 & 0.0097 & 0.0213 & 1.50 \\
\hline All & 1.00000 & 0.0242 & 0.0170 & 0.0198 & 1.88 \\
\hline
\end{tabular}

approximately lognormal and so the geometric mean and geometric standard deviation are calculated from the arithmetic mean (expected value) and arithmetic standard deviation reported by Ershow and Cantor (1989) (scc bottom row of Table B-1; method for computing the geometric mean and geometric standard deviation from the arithmetic mean and arithmetic standard deviation of a lognormal distribution appears immediately after Eq. B-1, which is in next section of this appendix addressing air-inhalation rate). This geometric mean and geometric standard deviation can then be introduced into Crystal Balt ${ }^{(1)}$, version 4.0 (Decisioneering, Inc., 1996) computer software to construct the composite lognormal distribution. The composite distribution is the one needed for performing Monte-Carlo simulations to address exposure and risk for someone picked at random from the population with an exposure duration likely to be experienced by the population at risk. The $95^{\text {th }}$-percentile 
upper-bound value for this approximately lognormal composite distribution of the ratio Ing can also easily be calculated from the geometric mean and geometric standard deviation appearing in the last row of Table B-1 (see Eq. B-1, which appears in the next section addressing air-inhalation rate).

The lifetime, TWA cdf for the ratio Ing is obtained by first constructing individual probability mass functions ( $\mathrm{pmfs}$ ) for each of the western-region age-group-specific distributions (see Table B-1). These distributions are considered approximately lognormal, so a geometric mean and geometric standard deviation for each age-group-specific distribution of Ing is derived from its respective arithmetic mean and arithmetic standard deviation reported by Ershow and Cantor (1989) (see Table B-1, and calculation procedure described after Eq. B-1 in next section addressing air-inhalation rate). Next, the geometric mean and geometric standard deviation for each age-group specific distribution is introduced into Crystal Ball ${ }^{\oplus}$, version 4.0 (Decisioneering, Inc., 1996) software in order to construct a corresponding age-group specific lognormal pmf. Then, the TWA cdf is obtained by performing the following procedure using Crystal Ball ${ }^{\circledR}$, version 4.0 (Decisioneering, Inc., 1996).

First, each of the age-specific lognormal pmfs is randomly sampled and each selected Ing is multiplied by its respective age-specific exposure-duration weighting factor (i.e., the applicable fraction of a 70-y lifetime, appearing in Table B-1). Following the sampling and weighting of each value, the weighted age-specific values are summed together to obtain a single lifetime, TWA value. This procedure is repeated 2000 times yielding 2000 equally likely TWA values. Because each of the 2000 TWA values are assumed to occur with equal probability, the expected value for the new TWA distribution is $2000^{-1}$ times the sum of the 2000 TWA values. To obtain the cdf from which the $95^{\text {th }}$-percentile upper bound is determined, the resulting 2000 TWA 
values can be listed in a spreadsheet in increasing order with their corresponding probabilities, which are each equal to $1 / 2000$. Then for each TWA value, the cumulative percentile value can be determined. As noted in the text, the expected value of this distribution is nearly equal to that of the composite distribution. The $95^{\text {th }}$-percentile upper bound value of Ing can be obtained directly from these listed values that describe the TWA cdf. As discussed in the text, this $95^{\text {th }}$-percentile upper-bound value of the TWA cdf is then used to obtain a deterministic estimate of the upper "conservative" bound for risk.

Inhalation rate of air [Inh; $\left.\mathrm{m}^{3} /(\mathrm{kg}-\mathrm{d})\right]$

The arithmetic mean and arithmetic standard deviation of the distribution of the ratio of age-specific inhalation rate to body weight was reported for California youth and adults in units of $\mathrm{L} /(\mathrm{kg}-\mathrm{d})$ by OEHHA (1996) [based on an evaluation of data collected by Adams (1993) and Wiley et al. (1991a,b); according to a discussion with Marty (1998)]. These two age-specific distributions were identified as being lognormal. Accordingly, a geometric mean and geometric standard deviation can be determined for each age-group-specific distribution (see Table B-2), and spreadsheet software can be employed to construct from these values complete lognormal cdfs. The composite distribution for the ratio $(\mathrm{Inh})$ of inhalation rate to body weight $\left[\mathrm{m}^{3} /(\mathrm{kg}-\mathrm{d})\right]$ is obtained from these cdfs using the respective age-specific population fractions as weighting factors. These weighting factors are represented by the age-adjusted population fractions shown in Table B-2, and they were determined from US Census Bureau data (USCB, 1998). 
Table B-2. Weighting factors and age-specific ratios (Inhs) of inhalation rates to body weights $\left[\mathrm{L} /(\mathrm{kg}-\mathrm{d})\right.$ or $\left.\mathrm{m}^{3} /(\mathrm{kg}-\mathrm{d})\right]$ used for constructing respective composite and lifetime, time-weighted-average (TWA) distributions [from Tables 3.19 and 3.20 in OEHHA (1996)]. To convert $\mathrm{L} /(\mathrm{kg}-\mathrm{d})$ to units of $\mathrm{m}^{3} /(\mathrm{kg}-\mathrm{d})$, divide $\mathrm{L} /(\mathrm{kg}-\mathrm{d})$ by $1000 \mathrm{~L} / \mathrm{m}^{3}$.

\begin{tabular}{|c|c|c|c|c|c|c|}
\hline $\begin{array}{l}\text { Age } \\
\text { (y) }\end{array}$ & $\begin{array}{l}\text { Age- } \\
\text { adjusted } \\
\text { population } \\
\text { fraction } \\
\text { weighting } \\
\text { factor }^{\mathrm{a}}\end{array}$ & $\begin{array}{l}\text { Exposure- } \\
\text { duration } \\
\text { weighting } \\
\text { factor }\end{array}$ & $\begin{array}{l}\text { Arith- } \\
\text { metic } \\
\text { mean } \\
{[\mathrm{L} /(\mathrm{kg}-\mathrm{d})]}\end{array}$ & $\begin{array}{l}\text { Arith- } \\
\text { metic } \\
\text { standard } \\
\text { deviation } \\
\text { [L/(kg-d)] }\end{array}$ & $\begin{array}{l}\text { Geo-metric } \\
\text { mean } \\
{\left[\mathrm{m}^{3} /(\mathrm{kg}-\mathrm{d})\right]}\end{array}$ & $\begin{array}{l}\text { Geo-metric } \\
\text { standard } \\
\text { deviation } \\
{\left[\mathrm{m}^{3} /(\mathrm{kg}-\mathrm{d})\right]}\end{array}$ \\
\hline $\begin{array}{l}0 \text { to } \\
12\end{array}$ & $\begin{array}{l}\frac{46,618,155}{270,732,000} \\
=0.172193\end{array}$ & $\begin{array}{l}12 / 70= \\
0.17143\end{array}$ & 452 & 67.73 & 0.4470 & 1.1607 \\
\hline $\begin{array}{l}12 \text { to } \\
70\end{array}$ & $\begin{array}{l}\underline{224,113,845} \\
270,732,000 \\
=0.827807\end{array}$ & $\begin{array}{l}58 / 70= \\
0.82857\end{array}$ & 225.2 & 64.634 & 0.2165 & 1.3249 \\
\hline
\end{tabular}

a Age-adjusted weighting factor is obtained from population fraction for similar age categories of US population (USCB, 1998).

The procedure that is performed with spreadsheet software to construct this composite distribution for Inh begins by employing Eq. B-1 to estimate the value of Inh corresponding to intervals of 0.01 probability (i.e., between 0 and 1.0 ) for each of the two age-specific lognormal distributions (see Table B-2).

$$
\operatorname{Inh} h_{\mathrm{p}}=\mathrm{GM} \times \mathrm{GSD}^{z_{\mathrm{p}}}, \text { where }
$$

$\operatorname{Inh} h_{\mathrm{p}}=$ daily inhalation rate per $\mathrm{kg}$ body weight $[\mathrm{L} /(\mathrm{kg}-\mathrm{d})]$ for cumulative increments of probability, $\mathrm{p}$, where each probability interval equals 0.01 for $0 \leq \mathrm{p} \leq 1.00$;

$\mathrm{GM}=$ geometric mean of the distribution: $\mathrm{GM}=\left(\mu^{2}\right) \times\left[\left(\mu^{2}\right)+\left(\tilde{\sigma}^{2}\right)\right]^{-0.5}$, where $\mu$ is the arithmetic mean and $\tilde{\sigma}$ is the arithmetic standard deviation of the parent distribution;

GSD = geometric standard deviation of the distribution: GSD $=\exp \left\{\ln \left[1+\left(\tilde{\sigma}^{2} / \mu^{2}\right)\right]\right\}^{-0.5}$, where $\mu$ is the arithmetic mean and $\tilde{\sigma}$ is the arithmetic standard deviation of the parent distribution;

$z_{\mathrm{p}} \quad=\Phi^{-1}(\mathrm{p})$, where $\Phi$ is the cumulative standard normal distribution function. 
Next, the computed values of Inh for both distributions are then combined together and listed in ascending order in one column of the spreadsheet. For each of these Inh values a cumulative probability is calculated for each age-group-specific distribution, and these results can be placed into two adjoining columns of the spreadsheet. The cumulative probability is obtained by rearranging the terms in Eq. B-1 so that the age-group-specific z score corresponding to each value of Inh is determined and the appropriate spreadsheet function can then be applied to determine the corresponding cumulative probability for that age-group-specific $z$ score. The cumulative probability in each age-group-specific distribution, which corresponds to the same value of Inh, is then multiplied by its applicable weighting factor represented by the age-adjusted fraction of the population. These producls from each age-groupspecific distribution are summed together to obtain a weighted average of cumulative probability that corresponds to each value of the ratio $\operatorname{Inh}$. The resulting list of 100 paired (Inh and weighted-average cumulative probability) values is the composite cdf that can be introduced into Crystal Ball ${ }^{(}$, version 4.0 (Decisioneering, Inc., 1996) software for performing Monte-Carlo simulations to address someone picked at random from the population with an exposure duration likely to be experienced by the population at risk.

The TWA cdf is obtained by performing the following procedure using Crystal Ball $^{\circledR}$, version 4.0 (Decisioneering, Inc., 1996) software. First, the pmfs for each agespecific lognormal distribution are created using the geometric means and geometric standard deviations of these distributions (from Table B-2) in Crystal Ball ${ }^{\circledR}$, version 4.0 (Decisioneering, Inc., 1996) software. Then, the TWA cdf is obtained by performing the following procedure using Crystal Ball ${ }^{\circledR}$, version 4.0 (Decisioneering, Inc., 1996). 
First, each of the age-specific lognormal pmfs is randomly sampled and each selected Inh is multiplied by its respective age-specific exposure-duration weighting factor (i.e., applicable fraction of a 70-y lifetime, appearing in Table B-2). Following the sampling and weighting of each value, the (two, in this case) weighted age-specific values are summed together to obtain a single lifetime, TWA value. This procedure is repeated 2000 time so that 2000 equally likely TWA values are obtained. Because each of the 2000 TWA values are assumed to occur with equal probability, the expected value for the new TWA distribution is $2000^{-1}$ times the sum of the 2000 TWA values. As noted in the text, the expected value of this distribution is equal to that of the composite distribution. To obtain the cdf from which the $95^{\text {th }}$-percentile upper bound is determined, the resulting 2000 TWA values can be listed in a spreadsheet in increasing order with their corresponding probabilities, which are each equal to $1 / 2000$. Then for each TWA value, the cumulative percentile value can be determined and assigned. The $95^{\text {th }}$-percentile upper bound value of the ratio of inhalation rate to body weight can be obtained directly from these listed values that describe the TWA cdf. As discussed in the text, this $95^{\text {th }}$-percentile upper-bound value of the TWA cdf is then used to obtain a deterministic estimate of the upper "conservative" bound for risk.

Surface area per $\mathrm{kg}$ body weight $\left[A ; \mathrm{cm}^{2} /(\mathrm{kg} d)\right]$

The composite distribution for the ratio $(A)$ of surface area to body weight $\left(\mathrm{cm}^{2} / \mathrm{kg}\right)$ is constructed from data for three age-specific empirical distributions provided by Phillips et al. (1993) that appears in Table B-3. The procedure followed involves the following steps. First, all of the values of $A$ from all three distributions are 
Table B-3. Weighting factors and age-specfic ratios (As) of surface areas to body weights $\left(\mathrm{cm}^{2} / \mathrm{kg}\right)$ used for constructing respective composite and lifetime, time-weighted-average (TWA) distributions [from Table 4 in Phillips et al. (1993)].

\begin{tabular}{|c|c|c|c|c|c|c|c|c|c|c|}
\hline \multirow{2}{*}{$\begin{array}{l}\text { Age- } \\
\text { group } \\
\text { (y) }\end{array}$} & \multirow[t]{2}{*}{$\begin{array}{l}\text { Age- } \\
\text { adjusted } \\
\text { population } \\
\text { fraction } \\
\text { weighting } \\
\text { factor }^{\mathrm{a}}\end{array}$} & \multirow{2}{*}{$\begin{array}{l}\text { Exposure- } \\
\text { duration } \\
\text { weighting } \\
\text { factor }\end{array}$} & \multicolumn{8}{|c|}{$\begin{array}{l}\text { Percentile of age-group empirical } \\
\text { distributions and corresponding surface } \\
\text { area to body weight ratio }\left(\mathrm{cm}^{2} / \mathrm{kg}\right)\end{array}$} \\
\hline & & & 0 & 5 & 10 & 25 & 50 & 75 & 90 & 95 \\
\hline 0 to 2 & $\begin{array}{l}\frac{7,593,200}{270,732,000} \\
=0.028047\end{array}$ & $\begin{array}{l}2 / 70= \\
0.02857\end{array}$ & 421 & 470 & 507 & 563 & 617 & 719 & 784 & 846 \\
\hline 2 to 18 & $\begin{array}{l}\frac{62,239,800}{270,732,000} \\
=0.229894\end{array}$ & $\begin{array}{l}16 / 70= \\
0.22857\end{array}$ & 268 & 291 & 328 & 376 & 422 & 454 & 501 & 594 \\
\hline$\geq 18$ & $\begin{array}{l}\frac{200,899,000}{270,732,000} \\
=0.742059\end{array}$ & $\begin{array}{l}52 / 70= \\
0.74286\end{array}$ & 200 & 238 & 244 & 270 & 286 & 302 & 316 & 329 \\
\hline
\end{tabular}

${ }^{a}$ Age-adjusted weighting factor is obtained from population fraction for similar age categories of US population (USCB, 1998).

listed together in a spreadsheet and then sorted into ascending order. Then, for each age-specific group, the probability for each of the surface area to body weight ratios is assigned based on the data reported in Table B-3 for the specific age-group, or in the absence of a reported value, the value is computed by linear interpolation using Eq. B-2.

$$
P_{\mathrm{i}}=P_{1}+\left[\left(\frac{a_{\mathrm{i}}-a_{1}}{a_{2}-a_{1}}\right) \times\left(P_{2}-P_{1}\right)\right], \text { where }
$$

$P_{\mathrm{i}} \quad=$ probability (expressed as decimal) corresponding to the surface area to body weight ratio of interest (i.e., $a_{\mathrm{i}} ; \mathrm{cm}^{2} / \mathrm{kg}$ );

$P_{1} \quad=$ probability (expressed as decimal) associated with the surface area to body weight ratio that is just less than the one of interest and for which probability is known or has been calculated (i.e., $a_{1}$ ); 
$P_{2} \quad=$ probability (expressed as decimal) associated with surface area to body weight ratio that is just greater than the one of interest and for which probability is reported (i.e., $a_{2}$ );

$a_{\mathrm{i}}=$ surface area to body weight ratio of interest $\left(\mathrm{cm}^{2} / \mathrm{kg}\right) ;$

$a_{1}=$ surface area to body weight ratio that is just less than the one of interest and for which a probability value is reported or has been calculated $\left(\mathrm{cm}^{2} / \mathrm{kg}\right) ;$ and

$a_{2}=$ surface area to body weight ratio that is just greater than the one of interest and for which a probability value is reported $\left(\mathrm{cm}^{2} / \mathrm{kg}\right)$.

For example, for age-group 0 to $2 \mathrm{y}$ the values of $A$ from 200 to $421 \mathrm{~cm}^{2} / \mathrm{kg}$ all have probabilities equal to zero, and $422 \mathrm{~cm}^{2} / \mathrm{kg}$ is the first value of interest in that age group that is calculated by linear interpolation. This calculation is performed by substituting into Eq. B-2 values of $A$ equal to 422,421 , and $470 \mathrm{~cm}^{2} / \mathrm{kg}$ for terms $a_{\mathrm{i},}, a_{1}$, and $a_{2}$, respectively, and the corresponding probabilities for 421 and $470 \mathrm{~cm}^{2} / \mathrm{kg}$ for this age group for terms $P_{1}$ and $P_{2}$, respectively (i.e., 0 and 0.05), from Table B-3.

Similarly, for the age-group from 2 to $18 \mathrm{y}$ the values of $A$ from 200 to $268 \mathrm{~cm}^{2} / \mathrm{kg}$ all have probabilities equal to zero, and $270 \mathrm{~cm}^{2} / \mathrm{kg}$ is the first value in that age group that is calculated by linear interpolation. In this case, values of $A$ cqual to 270,268 , and $291 \mathrm{~cm}^{2} / \mathrm{kg}$ are substituted into Eq. B-2 for terms $a_{\mathrm{i}} a_{1}$ and $a_{2}$, respectively, along with the corresponding probabilities for 268 and $291 \mathrm{~cm}^{2} / \mathrm{kg}$ for this age group (see Table B-3) to represent terms $P_{1}$ and $P_{2}$, respectively (i.e., 0 and 0.05). A final example is for the last age group ( $\geq 18 \mathrm{y}$ ), where only $200 \mathrm{~cm}^{2} / \mathrm{kg}$ has a probability equal to zero, and the first value of $A$ to have its probability determined by linear interpolation is 268 $\mathrm{cm}^{2} / \mathrm{kg}$. In this last case, values of $A$ equal to 268,244 , and $270 \mathrm{~cm}^{2} / \mathrm{kg}$ are substituted into Eq. B-2 for terms $a_{\mathrm{i}} a_{1}$ and $a_{2}$, respectively, along with corresponding probabilities for 244 and $270 \mathrm{~cm}^{2} / \mathrm{kg}$ for this age group (see Table B-3) that represent terms $P_{1}$ and 
$P_{2}$, respectively (i.e., 0.10 and 0.25 ). This process is repeated in each age-group for values of $A$ for which interpolation must be performed.

The next step is to weight each age-group-specific cumulative probability that is associated with a particular value of $A$ by its appropriate age-adjusted population fraction (see Table B-3). Then, for each value of $A$, the sum of the products of agegroup-specific cumulative probabilities and applicable weighting factors equates to a weighted functional average cumulative probability. These resulting paired values of $A$ and corresponding weighted cumulative probabilities represent the composite cdf that can be inserted into Crystal Ball ${ }^{\boxplus}$, version 4.0 (Decisioneering, Inc., 1996) software for performing Monte-Carlo simulations to address someone picked at random from the population with an exposure duration likely to be experienced by the population at risk.

As was done for Ing and Inh, the TWA cdf for $A$ is obtained by performing the following procedure using Crystal Ball ${ }^{\circledR}$, version 4.0 (Decisioneering, Inc., 1996) software. First, the empirical cdfs reported by Phillips et al. (1993) are introduced into Crystal Ball version 4.0 (Decisioneering, Inc., 1996) software (in their cumulative form) and randomly sampled. The value $A$ from each distribution is then randomly sampled and multiplied by its respective age-specific exposure-duration weighting factor (i.e., applicable fraction of a 70-y lifetime, appearing in Table B-3). All of these weighted age-specific values are then summed to obtain a single TWA value. Then, this procedure is repeated 2000 times. Because each of the 2000 TWA values are assumed to occur with equal probability, the expected value for the new TWA distribution is $2000^{-1}$ times the sum of the 2000 TWA values. As noted in the text, the expected value of this distribution is equal to that of the composite distribution. To obtain the cdf from which the $95^{\text {th }}$-percentile upper bound is determined, the resulting 2000 TWA values can be listed in a spreadsheet in increasing order with their corresponding probabilities, which 
are each equal to $1 / 2000$. Then for each TWA value, the cumulative percentile value can be determined and assigned. The $95^{\text {th }}$-percentile upper bound value of the ratio of $A$ can be obtained directly from these listed values that describe the TWA cdf. As discussed in the text, this $95^{\text {th }}$-percentile upper-bound value of the TWA cdf is then used to obtain a deterministic estimate of the upper "conservative" bound for risk.

\section{Constructing the Student's T distribution for Applicable Degrees of Freedom}

The Student's T distribution for the applicable degrees of freedom $(n-1$, where $n$ is the number of available sample values) is easily constructed using spreadsheet software and an "inverse" Student's T function. The process followed involves listing very small equal intervals (e.g. $\leq 0.0025)$ in ascending order of cumulative probabilities between 0 and 1.0. Then for each cumulative probability, the value of the Student's T distribution is identified using the inverse Student's T distribution function with the applicable number of degrees of freedom. For the three reported concentrations of TCE in water (Purrier, 1997), the Student's T distribution has 2 degrees of freedom. For the 14 reported values of water-to-air transfer efficiency for showers running water at temperatures $\geq 30{ }^{\circ} \mathrm{C}$ (Corsi and Howard, 1998), the corresponding Student's $\mathrm{T}$ distribution has 13 degrees of freedom. These Student's $T$ distributions are then inserted into Crystal Ball ${ }^{\oplus}$, version 4.0 (Decisioneering, Inc., 1996) software, and used in performing Monte-Carlo simulations of the mean concentration of TCE in ground water (Eq. 4 in text), and the water-to-air transfer efficiency of TCE in shower water (Eq. 5 in text). 


\section{Constructing Distributions for Exposure Duration (i.e., Residence Time)}

The conservative approximation for the 95th percentile upper-bound of exposure duration (i.e., residence time), $\hat{E D}$, which is used to compute $\hat{R}_{\text {High }}$, equals $55.28 \mathrm{y}$. This upper-bound value reflects variability in total time of residence and is obtained directly by linear interpolation of the cumulative probability distribution for $1-R(t)^{f_{\mathrm{m}}^{*}}$. This distribution is constructed by solving for $R(\mathrm{t})^{f_{\mathrm{m}}^{*}}$ for time $(t)$ ranging from 0 to $70 \mathrm{y}$, in one year increments, and assigning $f_{\mathrm{m}}^{*}$ (i.e., fraction of moves outside the water supply district) the value equal to 0.439 , which is the 5 th percentile of its triangular distribution that ranges from $1 / 3$ to 1 with a mode at 2/3 (see also Eqs. 8 and 11 and Table 1 in this text]. The equation for $R(t)$ is from Israeli and Nelson (1992) and is shown as Eq. B-3.

$$
R(t)=\frac{e^{-\left[a_{1} b_{1}\left(1-e^{-\frac{t}{b_{1}}}\right)+a_{2} t+a_{3} b_{3}\left(e^{\frac{t}{b_{3}}}-1\right)\right]}}{a_{1}+a_{2}+a_{3}}\left(a_{1} e^{-\frac{t}{b_{1}}}+a_{2}+a_{3} e^{-\frac{t}{b_{3}}}\right), \text { where }
$$

$t$ equals time and the terms $a_{1}, b_{1} a_{2}, a_{3}$, and $b_{3}$ are nonnegative parameters equal to values of $0.2029,1.74,0.0832,0.008$, and 10.3 , respectively, for the western region of the US (as determined and presented by Israeli and Nelson, 1992).

The distribution for the population-average value of total residence time, $\overline{E D}$, is constructed using the following procedure. First, an approximate solution is obtained for the integral shown in Eq. 10 in text based on 2000 equal intervals of time $(t)$ between 0 and $70 \mathrm{y}$ (i.e., increments $=70 / 2000$ or $0.035 \mathrm{y}$ ), and a specific value of $f_{\mathrm{m}}$ selected at random from its triangular distribution using Crystal Ball ${ }^{\circledR}$, version 4.0 (Decisioneering, Inc., 1996) software. For example, 


$$
\overline{E D}_{\mathrm{j}} \approx \Delta t\left[\sum_{\mathrm{i}=2}^{\mathrm{n}-1} y_{\mathrm{i}}+\left(\frac{y_{1}+y_{\mathrm{n}}}{2}\right)\right] \quad \begin{aligned}
& \text { by linear approximation (the } \\
& \text { "trapezoidal rule"), }
\end{aligned}
$$

where $\mathrm{n}=2000$ equal intervals of time between 0 and $70 \mathrm{y}, y_{\mathrm{i}}=R\left(\mathrm{t}_{\mathrm{i}}\right)^{f_{\mathrm{m}_{\mathrm{i}}}}$ at an $i$ th increment of time corresponding to a specific interval of $0.035 \mathrm{y}$ from 0 to $70 \mathrm{y}$, and any $j$ th value of $f_{\mathrm{m}}$ selected at random from its triangular distribution using Crystal Ball ${ }^{\circledast}$, version 4.0 (Decisioneering, Inc., 1996) software. For odd values of n (e.g., 2001), a better parabolic, approximation (Simpson's Rule) may be used:

$$
\overline{E D}_{\mathrm{j}} \approx \frac{\Delta t}{3}\left[y_{1}+2\left(\sum_{\mathrm{i}=1}^{\frac{\mathrm{n}-3}{2}} 2 y_{2 \mathrm{i}}+y_{2 \mathrm{i}+1}\right)+4 y_{\mathrm{n}-1}+y_{\mathrm{n}}\right]
$$

In either case, the process is then repeated for $n-1$ more randomly selected $j$ th values of $f_{\mathrm{m}}$. The resulting $\mathrm{n}$ values of $\overline{E D}$ are then listed in ascending order, and assigned a cumulative probability based on each value being assumed to occur with an equal likelihood of $1 / 2000$ (or 0.0005 ). The expected value for this distribution (in this case approximately $7.6 \mathrm{y}$ ) is therefore the sum of the $\overline{E D}$ values divided by 2000 . This cdf is then used for Monte-Carlo simulations requiring $\overline{E D}$. However, note that only about 400 paired values for any distribution can be inserted into Crystal Ball ${ }^{\circledR}$, version 4.0 (Decisioneering, Inc., 1996) software to create a distribution for sampling. Therefore, the cdf in the spreadsheet must be reduced in size and described by only 400 equal probability intervals of 0.0025 , which can be selected from the listed values. The $95^{\text {th }}$-percentile upper bound for this distribution can be obtained from the listed values for the cdf. 
The distribution of the cumulative probability reflecting variability in total time of residence, $\langle E D\rangle$, is obtained using Eq. 12 in the text, with time $(t)$ increasing in intervals of $0.1 \mathrm{y}$ from 0 to $10 \mathrm{y}$, increasing in intervals of $1 \mathrm{y}$ from 11 to $50 \mathrm{y}$, and increasing in intervals of 5 years from 55 to $70 \mathrm{y}$. This list of time vs. probability values is then used in Crystal Ball ${ }^{\circledR}$, version 4.0 (Decisioneering, Inc., 1996) software for performing Monte-Carlo simulations. The expected value and 95th percentile upper bound for this distribution are obtained by using Crystal Ball ${ }^{\oplus}$, version 4.0 (Decisioneering, Inc., 1996) software to perform a Monte-Carlo simulation involving 2000 or more trials and having it report the expected (mean) and $95^{\text {th }}$-percentile upperbound values for the resulting distribution.

\section{Exposure and Traditional Risk-Related (point) Estimators}

The input parameters, corresponding values, and respective resulting deterministically calculated exposure $\left(E_{\mathrm{Ing}} E_{\mathrm{Inh}}\right.$ and $\left.E_{\text {Derm }}\right)$ and traditional risk-related ( $\hat{R}_{\mathrm{E}}$, "best" estimate; $\hat{R}_{\mathrm{RME}}$, risk to "reasonably maximum exposed" person; and $\hat{R}_{\mathrm{High}}$, upper "conservative" bound) (point) estimators are presented in Table B-4. The purpose of Table B-4 is to summarize the specific inputs and outputs associated with deterministically calculating these exposure and traditional risk-related estimators using Eqs. 1 through 3 and Eq. 13 in the text.

\section{Determining $P_{0}$ Using Simulated $\bar{R}$ Values}

The probability, $P_{0}$, that there will be no additional cases of cancer in a given population, $n_{\mathrm{T}}$ over a 70-y period, is approximated as follows. First, 2000 values of $\bar{R}$ are generated using a Monte-Carlo simulation of 2000 trials. A corresponding 
Table B-4. Input parameters, corresponding values, and respective resulting deterministically calculated exposure $\left(E_{\mathrm{Ing} g^{\prime}} E_{\mathrm{Inh}}\right.$, and $\left.E_{\mathrm{Derm}}\right)$ and traditional risk-related ( $\hat{R}_{\mathrm{E}}$, "best" estimate; $\hat{R}_{\mathrm{RME}}$, risk to "reasonably maximum exposed" person; and $\hat{R}_{\text {High }}$, upper "conservative" bound) (point) estimators.

\begin{tabular}{|c|c|c|c|c|}
\hline $\begin{array}{l}\text { Inputs and corresponding } \\
\text { estimates of } \\
\text { exposure and risk }\end{array}$ & $\begin{array}{l}\text { Distribution } \\
\text { represents }^{b}\end{array}$ & $\begin{array}{c}\text { Related } \\
\text { to } \hat{R}_{\mathrm{E}}{ }^{c}\end{array}$ & $\begin{array}{l}\text { Related to } \\
\hat{R}_{\mathrm{RME}}{ }^{\mathrm{d}}\end{array}$ & $\begin{array}{l}\text { Related to } \\
\hat{R}_{\mathrm{High}}{ }^{\mathrm{e}}\end{array}$ \\
\hline$E F(\mathrm{~d} / \mathrm{y})$ & NA (constant) & 350 & 350 & 350 \\
\hline$A T$ (d in 70-y lifespan) & NA (constant) & 25,550 & 25,550 & 25,550 \\
\hline$E D(\mathrm{y})$ & JUV & $7.6^{\mathrm{f}}$ & $30^{\mathrm{g}}$ & $55.3^{\mathrm{h}}$ \\
\hline$C_{w}(\mathrm{mg} / \mathrm{L})$ & Uncertainty & 0.0223 & 0.0223 & 0.0301 \\
\hline $\operatorname{Ing}(\mathrm{L} / \mathrm{kg}-\mathrm{d})$ & Variability & 0.0242 & $0.0286^{\mathrm{g}}$ & 0.0399 \\
\hline$E_{\text {Ing }}[\mathrm{mg} / \mathrm{kg}-\mathrm{d}]$ & NA & $5.6 \times 10^{-5}$ & $2.6 \times 10^{-4}$ & $9.1 \times 10^{-4}$ \\
\hline$C S F_{\text {Ing }}\{R /[\mathrm{mg} /(\mathrm{kg}-\mathrm{d})]\}$ & NA (constant) & 0.015 & 0.015 & 0.015 \\
\hline $\begin{array}{l}\text { Traditional risk-related } \\
\text { (point) estimators for } \\
\text { ingestion pathway }\end{array}$ & $\mathrm{N} \Lambda$ & $8.4 \times 10^{-7}$ & $3.9 \times 10^{-6}$ & $1.4 \times 10^{-5}$ \\
\hline$E F(\mathrm{~d} / \mathrm{y})$ & NA (constant) & 350 & 350 & 350 \\
\hline$A T$ (d in 70-y lifespan) & NA (constant) & 25,550 & 25,550 & 25,550 \\
\hline$E D(\mathrm{y})$ & JUV & $7.6^{\mathrm{f}}$ & $30^{g}$ & $55.3^{\mathrm{h}}$ \\
\hline$C_{w}(\mathrm{mg} / \mathrm{L})$ & Uncertainty & 0.0223 & 0.0223 & 0.0301 \\
\hline $\operatorname{Inh}\left[\mathrm{m}^{3} /(\mathrm{kg}-\mathrm{d})\right]$ & Variability & 0.264 & $0.286^{\mathrm{g}}$ & 0.363 \\
\hline$W_{\mathrm{sh}}$ and $W_{\mathrm{b}}(\mathrm{L} / \mathrm{h})$ & Variability & 480 & 777 & 777 \\
\hline$W_{\mathrm{h}}(\mathrm{L} / \mathrm{h})$ & Variability & 42 & 69.9 & 69.9 \\
\hline$\phi_{\text {TCE-sh }}$ (dimensionless) & Variability & 0.76 & 0.81 & 0.81 \\
\hline$\phi_{\text {TCE-h }}\left(\right.$ dimensionless) ${ }^{\mathrm{i}}$ & Variability & 0.59 & 0.63 & 0.63 \\
\hline$A E_{\mathrm{sh}}\left(\mathrm{m}^{3} / \mathrm{h}\right)$ & Variability & 9.94 & 4.82 & 4.82 \\
\hline$A E_{\mathrm{b}}\left(\mathrm{m}^{3} / \mathrm{h}\right)$ & Variability & 39.1 & 14.6 & 14.6 \\
\hline$A E_{\mathrm{h}}\left(\mathrm{m}^{3} / \mathrm{h}\right)$ & Variability & 649 & 344 & 344 \\
\hline
\end{tabular}


Table B-4 (continued).

\begin{tabular}{|c|c|c|c|c|}
\hline $\begin{array}{l}\text { Inputs and corresponding } \\
\text { estimates of } \\
\text { exposure and risk }\end{array}$ & $\begin{array}{l}\text { Distribution } \\
\text { represents }^{\mathrm{b}}\end{array}$ & $\begin{array}{l}\text { Related } \\
\text { to } \hat{R}_{\mathrm{E}}{ }^{\mathrm{c}}\end{array}$ & $\begin{array}{l}\text { Related to } \\
\hat{R}_{\mathrm{RME}}{ }^{\mathrm{d}}\end{array}$ & $\begin{array}{l}\text { Related to } \\
\hat{R}_{\text {High }}{ }^{\text {e }}\end{array}$ \\
\hline$E T_{\mathrm{sh}}(\mathrm{h} / \mathrm{d})$ & Variability & 0.129 & $0.13^{g}$ & 0.226 \\
\hline$E T_{\mathrm{b}}(\mathrm{h} / \mathrm{d})$ & Variability & 0.330 & 0.744 & 0.744 \\
\hline$E T_{\mathrm{b}}(\mathrm{h} / \mathrm{d})$ & Variability & 14 & $16.4^{\mathrm{g}}$ & 19.4 \\
\hline$D(\mathrm{~h} / \mathrm{d})^{\mathrm{j}}$ & NA (constant) & 24 & 24 & 24 \\
\hline$E_{\text {Inh }}[\mathrm{mg} / \mathrm{kg}-\mathrm{d}]$ & NA & $2.1 \times 10^{-4}$ & $5.6 \times 10^{-3}$ & $2.2 \times 10^{-2}$ \\
\hline$C S F_{\text {Ing }}\{R /[\mathrm{mg} /(\mathrm{kg}-\mathrm{d})]\}$ & NA (constant) & 0.010 & 0.010 & 0.010 \\
\hline $\begin{array}{l}\text { Traditional risk-related } \\
\text { (point) estimators for } \\
\text { inhalation pathway }\end{array}$ & NA & $2.1 \times 10^{-6}$ & $5.6 \times 10^{-5}$ & $2.2 \times 10^{-4}$ \\
\hline$E F(\mathrm{~d} / \mathrm{y})$ & NA (constant) & 350 & 350 & 350 \\
\hline$A T$ (d in 70-y lifespan) & NA (constant) & 25,550 & 25,550 & 25,550 \\
\hline$E D(\mathrm{y})$ & JUV & $7.6^{\mathrm{f}}$ & $30^{\mathrm{g}}$ & $55.3^{\mathrm{h}}$ \\
\hline$C_{\mathrm{w}}(\mathrm{mg} / \mathrm{L})$ & Uncertainty & 0.0223 & 0.0223 & 0.0301 \\
\hline$\phi_{\text {TCE-sh }}$ (dimensionless) & Variability & 0.76 & 0.81 & 0.81 \\
\hline$A\left(\mathrm{~cm}^{2} / \mathrm{kg}\right)$ & Variability & 326 & $329^{g}$ & 373 \\
\hline$f_{\mathrm{s}}($ dimensionless $)$ & Variability & 0.65 & 0.875 & 0.875 \\
\hline$k_{\mathrm{p}}(\mathrm{cm} / \mathrm{h})$ & Variability & 0.263 & 0.293 & 0.293 \\
\hline$E T_{\mathrm{sh}}(\mathrm{h} / \mathrm{d})$ & Variability & 0.129 & $0.13^{g}$ & 0.226 \\
\hline $\mathrm{cf}\left(\mathrm{L} / \mathrm{cm}^{3}\right)^{\mathrm{k}}$ & Constant & 0.001 & 0.001 & 0.001 \\
\hline$E_{\text {Derm }}[\mathrm{mg} / \mathrm{kg}-\mathrm{d}]$ & NA & $1.0 \times 10^{-5}$ & $6.0 \times 10^{-5}$ & $2.9 \times 10^{-4}$ \\
\hline$C S F_{\text {Derm }}\{R /[\mathrm{mg} /(\mathrm{kg}-\mathrm{d})]\}^{\prime}$ & NA (constant) & 0.015 & 0.015 & 0.015 \\
\hline $\begin{array}{l}\text { Traditional risk-related } \\
\text { (point) estimators for } \\
\text { dermal absorption } \\
\text { pathway }\end{array}$ & NA & $1.5 \times 10^{-7}$ & $9.0 \times 10^{-7}$ & $4.4 \times 10^{-6}$ \\
\hline
\end{tabular}


Table B-4 (continued).

\begin{tabular}{|c|c|c|c|c|}
\hline $\begin{array}{l}\text { Inputs and corresponding } \\
\text { estimates of } \\
\text { exposure and risk }\end{array}$ & $\begin{array}{l}\text { Distribution } \\
\text { represents }^{\mathrm{b}}\end{array}$ & $\begin{array}{l}\text { Related } \\
\text { to } \hat{R}_{\mathrm{E}}{ }^{c}\end{array}$ & $\begin{array}{l}\text { Related to } \\
\hat{R}_{\mathrm{RME}}{ }^{\mathrm{d}}\end{array}$ & $\begin{array}{c}\text { Related to } \\
\hat{R}_{\mathrm{High}}\end{array}$ \\
\hline $\begin{array}{l}\text { Total for traditional } \\
\text { risk-related estimators } \\
\text { (i.e., sum for all } \\
\text { pathways })^{\mathrm{m}}\end{array}$ & NA & $3.1 \times 10^{-6}$ & $6.1 \times 10^{-5}$ & $2.4 \times 10^{-4}$ \\
\hline
\end{tabular}

a Symbols are defined in Table 1 and/or Eqs. 1 through 3 in text.

${ }^{b}$ From Table 1 and/or Eqs. 1 through 3 in text; NA = not applicable with respect to a distribution representation because value is either a constant or a deterministically calculated point estimate.

${ }^{c}$ Expected values (from Table 1 in text) are used for variates (and similarly for the calculations of $\langle\bar{R}\rangle$ and $\overline{\langle R\rangle}$ using exact expressions).

${ }^{d}$ As noted in footnote to Table 2 in text: if available, regulatory default values (see data in Table 2 in text) are used for variates; otherwise, expected values (from Table 1 in text) are used for uncertain variates and $95^{\text {th }}$-percentile upper-bound values (from Table 1 in text) are used for heterogeneous ones (or in the case of air-exchange rates only, and for reasons explained in footnote " $\mathrm{c}$ " of Table 1 in text, the $5^{\text {th }}$-percentile values are used).

e The $95^{\text {th }}$-percentile upper-bound values (from Table 1 in text) are used for variates (or in the case of air-exchange rates only, and for reasons explained in footnote "c" of Table 1 in text, the $5^{\text {th }}$-percentile values are used).

f This expected value is discussed in this appendix and also mentioned in the footnote to Table 4 in text.

${ }^{\mathrm{g}}$ Regulatory value (based on data presented in Table 2 in text).

${ }^{\text {h }}$ Approximation for $95^{\text {th }}$-percentile upper-bound of exposure duration, $\hat{E D}$ [see explanation in this appendix; and see also Eqs. 8 and 11 and Table 1 in text).

${ }^{i}$ Calculation of term explained after Eq. 2 in text.

i Term is described after Eq. 2 in text.

${ }^{k}$ Term is described after Eq. 3 in text.

${ }^{1}$ For purposes of this analysis the ingestion cancer slope factor $\left(C S F_{\text {Ing }}\right)$ is also considered to apply to dermal absorption $\left(C S F_{\text {Derm }}\right)$, based on regulatory guidance (see Eq. 13 and discussion that follows in text, and Tables 1 and 2 in text).

${ }^{m}$ These totals for the traditional risk-related (point) estimators are listed in Table 3 in text. (The values for exposure intakes: $E_{\mathrm{Ing} g^{\prime}} E_{\mathrm{Inh}{ }^{\prime}}$ and $E_{\mathrm{Derm}{ }^{\prime}}$ are not presented in text.) 
value of $e^{-n_{\mathrm{T}} \bar{R}}$ is computed for each of the $2000 \bar{R}$ values conditional on a specific total population size $n_{\mathrm{T}}$ (see Table 4 in text). Because each of these values is assumed to have an equal probability of occurrence of $1 / 2000$ (i.e., 0.0005 ), the 2000 values of $e^{-n_{\mathrm{T}} \bar{R}}$ can be summed and multiplied by $1 / 2000$ to obtain a value for $P_{0}$, which is the solution to the integral shown in Eq. 18 in text. Repeating this process 10 times for each value of $n_{\mathrm{T}}$ makes it possible to oblain a mean value and to compute a CVM (in percent) for a $P_{0}$ and value of $n_{\mathrm{r}}$. As explained in the text, the value of $1-P_{0}$ represents the probability that for a given population $n_{\mathrm{T}}$ there will be one or more (i.e., more than zero) additional cases of cancer (i.e., the probability that $N \geq 1$ ). The expected number of cases is defined as $\langle N\rangle=n_{\mathrm{T}} \times\langle\bar{R}\rangle$, which is not necessarily an integer. 


\section{REFERENCES FOR APPENDIX B}

Adams, W. (1993), Measurement of Breathing Rate and Volume in Routinely Performed Daily Activities, prepared for California Air Resources Board, Research Division, Sacramento, CA.

Corsi, R.L., and C. Howard (1998), Shower Database, in Volatilization Rates From Water to Indoor Air: Phase II, prepared for United States Environmental Protection Agency, Office of Research and Development, The National Center for Environmental Assessment, Washington, DC (Technical Merit Review Draft, released for citation by J. Moya, EPA Project Officer) Grant Number CR 824228-01, pp. 167-193.

Decisioneering, Inc. (1996), Crystal Ball ${ }^{\oplus}$, Forecasting and Risk Analysis for Spreadsheet Users, Version 4.0, Decisioneering, Inc., Denver, CO.

Ershow, A.G., and K.P. Cantor (1989), Total Water and Tapwater Intake in the United States: Population-Based Estimates of Quantities and Sources, prepared under National Cancer Institute Order \#263-MD-810264 by the Life Sciences Research Office, Federation of American Societies for Experimental Biology, Bethesda MD.

Israeli, M., and C.B. Nelson (1992), Distribution and Expected Time of Residence for U.S. Households, Risk Analysis 12(1): 65-72.

Marty, M. (1998), Personal Communication Regarding the Methodology Used by OEHHA Staff to Develop Breathing Rate per Unit Body Weight Distribution From Data of Adams (1993) and Wiley et al. (1991a,b) and Presented in OEHHA (1996), Office of Environmental Health Hazard Assessment (OEHH $\Lambda$ ), California Environmental Protection Agency, Berkeley CA.

Office of Environmental : Health Hazard Assessment (OEHHA), California Environmental Protection Agency (1996), Exposure Assessment and Stochastic Analysis, Air Toxics Hot Spots Program, Risk Assessment Guidelines Part IV, Technical Support Document, Public Review Draft, Office of Environmental Health Hazard Assessment, California Environmental Protection Agency, Berkeley, CA.

Phillips, L.J., R.J. Fares, and L.G. Schweer (1993), Distributions of Total Skin Surface Area to Body Weight Ratios for Use in Dermal Exposure Assessments, J. Exposure Analysis Environ. Epidem. 3(5):331-338.

Purrier, W. (1997), Personal Communication Regarding Detailed Data for TCE Groundwater Concentration at USAF Site in Northern California, Law Engineering and Environmental Services, Inc., Sacramento, CA (December 1997).

United States Census Bureau (USCB) (1998), Resident Population of the United States: Estimates by Age and Sex, source: United States Population Estimates, by Age, Sex, Race, and Hispanic Origin, 1990 to 1997 (with associated updated tables for recent months), last revised December 28, 1998, Population Division, US Bureau of the Census, Washington, DC, available online at http://www.census.gov/population/ estimates/nation/intfile2-1.txt, May 3, 1999. 
Wiley, J.A., J.P. Robinson, T. Piazza, K. Garrett, K. Cirksena, Y.T. Cheng, and G. Martin (1991a), Activity Patterns of California Residents, prepared for California Air Resources Board, Research Division, ARB/R-93/487, Sacramento, CA (available from National Technical Information Service, Springfield, VA).

Wiley, J.A., J.P. Robinson, Y.T. Cheng, T. Piazza, L. Stork, and K. Pladsen (1991b), Study of Children's Activity Patterns, prepared for California Air Resources Board, Research Division, ARB/9-93/489, Sacramento, CA (available from National Technical Information Service, Springfield, VA). 